\title{
Calcium's Role in Mechanotransduction during Muscle Development
}

\author{
Tatiana Benavides Damma,b Marcel Egli ${ }^{a}$
}

${ }^{a}$ CC Aerospace Biomedical Science \& Technology, Space Biology Group, Luzern University of Applied Sciences and Arts, Hergiswil, 'Institute for Biomechanics, Eidgenössische Technische Hochschule Zürich, Zürich, Switzerland

\section{Key Words}

Mechano-gated calcium channels $•$ Calcium signaling $\bullet$ Mechanical forces $\bullet$ Mechanosensation - Mechanoresponses • Muscle atrophy • Muscle dystrophy

\begin{abstract}
Mechanotransduction is a process where cells sense their surroundings and convert the physical forces in their environment into an appropriate response. Calcium plays a crucial role in the translation of such forces to biochemical signals that control various biological processes fundamental in muscle development. The mechanical stimulation of muscle cells may for example result from stretch, electric and magnetic stimulation, shear stress, and altered gravity exposure. The response, mainly involving changes in intracellular calcium concentration then leads to a cascade of events by the activation of downstream signaling pathways. The key calcium-dependent pathways described here include the nuclear factor of activated $T$ cells (NFAT) and mitogen-activated protein kinase (MAPK) activation. The subsequent effects in cellular homeostasis consist of cytoskeletal remodeling, cell cycle progression, growth, differentiation, and apoptosis, all necessary for healthy muscle development, repair, and regeneration. A deregulation from the normal process due to disuse, trauma, or disease can result in a clinical condition such as muscle atrophy, which entails a significant loss of muscle mass. In order to develop therapies against such diseased states, we need to better understand the relevance of calcium signaling and the downstream responses to mechanical forces in skeletal muscle. The purpose of this review is to discuss in detail how diverse mechanical stimuli cause changes in calcium homeostasis by affecting membrane channels and the intracellular stores, which in turn regulate multiple pathways that impart these effects and control the fate of muscle tissue.
\end{abstract}




\section{Introduction}

Many physiological functions such as embryonic development, hearing, touch sensitivity, kidney function, vascular tone and muscle stretch depend on the ability of cells to sense and react to mechanical stimuli [1,2]. Defects in mechanotransduction are involved in the development of many diseases, including muscular dystrophies, cardiomyopathies, and cancer. These defects may appear as deficits in cellular structure and organization, impairing mechanosensation, or as mutations or deregulations in the proteins involved in the downstream signaling pathways directly affecting the normal mechanoresponse. It is therefore of utmost importance to identify the molecular components encompassing normal and defective mechanostransduction, in order to improve our understanding of faulty mechanisms and consequently develop efficient therapeutic strategies against such diseases.

\section{Mechanotransduction}

Mechanotransduction is a process where cells adapt to their physical surroundings by sensing their environment and translating the mechanical input into biochemical signals. It is a fundamental process that allows the conversion of physical forces into an appropriate cellular response. The mechanical input sensed by the cell can be any force applied to the cell itself, such as stretching or straining the cell membrane, unloading or overloading the cells through changes in gravitational forces and even exposure to electromagnetic fields. The sensing of the mechanical stimuli is based on force-induced conformational changes in mechanosensitive proteins that detect an alteration in the cellular structure. Cells sense the mechanical forces through cell-cell interactions, cell organelles embedded into the cytoskeleton, and cell-substrate interactions. Several molecules which are not mutually exclusive have been proposed to act as biological mechanosensors, including stretchactivated ion channels (SACs) at the cell membrane, transmembrane adhesion receptors that link the cytoskeleton to the extracellular matrix (ECM) and to other cells (like integrins and integrin-associated proteins), sarcomeric proteins (such as titin and myosin) and cell surface receptors (reviewed in $[3,4]$ ). According to the tensegrity model, cells sense the mechanical input through surface receptors and immediately respond as the cellular scaffold transduces the signal [5].

\section{Muscle development}

Cells, tissues and organisms are all exposed to internal and external physical forces [6, 7]. The recognition and response to mechanical stimuli is essential in the development and proper function of a variety of cell types and tissues, including the musculoskeletal system. In certain cell types called mechanocytes, such as osteoblasts and myoblasts, mechanical signals deeply impact their gene expression [8, 9]. According to Wolff's law, bone remodeling is achieved in response to loading [10]. Similar to bone, it is well-known that skeletal muscle is responsive to mechanical stimulation, having the inherent ability to adapt its structure, metabolism and function in response to activity [8]. In particular, stretch has been shown to be a major mechanical input that up-regulates protein synthesis and promotes muscle growth [11]. Additionally, as it will become apparent in this review, a variety of studies have been performed in humans, animals and cell line models by using exercise, electric and magnetic stimulation, shear stress, disease states and altered gravity exposure to understand the consequences of these diverse conditions in muscle functionality. Muscle tissue being sensitive to mechanical force responds by activating diverse signaling pathways, mainly regulated by calcium that lead to changes in its developmental program $[12,13]$.

Skeletal muscle has been classified into fiber types depending on their contraction speed and metabolic capacity. In general, the three classical fiber types are slow-twitch oxidative (type I), fast-twitch oxidative/glycolytic (type IIA), and fast-twitch glycolytic (type IIB) (reviewed in [14]). Type I fibers are known as slow-twitch fibers because they exert a slow contraction involving the type I myosin heavy chain (MHC). These fibers exhibit abundance in mitochondria, an oxidative metabolism and a high resistance to fatigue. In contrast, type II 
myofibers are called fast-twitch myofibers because they exert fast contractions, experience fatigue quickly and are mainly glycolytic. The slow fibers are used for endurance and posture maintenance while the fast fibers are for strength and speed. The fiber type is determined by the expression of contractile and regulatory proteins, as well as metabolic enzymes [15].

Myogenesis is a process in which muscle precursor cells or myoblasts proliferate, and then differentiate fusing into multinucleated myotubes. It is essential for muscle growth, maintenance and repair in case of injuries [16]. A faulty regulation in myogenesis leads to muscle atrophy, characterized by a decrease in muscle mass resulting from disuse, disease or injury. Two main conditions associated with muscle atrophy are sarcopenia and cachexia (reviewed in [14]). Sarcopenia encompasses a chronic loss of muscle mass and strength in the aging population, while cachexia leads to severe muscle wasting due to damage in the nerve associated with muscle. In addition, space atrophy also describes a reduction in muscle mass and strength, as a result of mechanical unloading from the force of gravity. In these cases, the breakdown rate of proteins exceeds their rate of synthesis. In all of these conditions, decreased activity results in further loss, creating a vicious cycle between disuse and increased muscle wasting. Muscle tissue is critical in numerous life-sustaining processes, not only for producing movement, but also for storing metabolites, aiding in tissue repair, regulating body temperature, and generating the mechanical strain contributing to bone maintenance (reviewed in [17]). In addition, skeletal muscle is the most abundant tissue of the human body; consequently the whole body metabolism is affected by muscle atrophy, leading to the development of other diseases (reviewed in [18]). As it is clear that a significant loss of muscle mass is life threatening [19], successful treatments need to be designed in order to alleviate these clinical scenarios, firstly however the causal mechanisms that mediate muscle atrophy need to be better understood.

Studying the underlying mechanisms that regulate muscle development under actual and simulated microgravity exposure is crucial for the identification of the causes and countermeasures for muscle atrophy in earth-bound clinical scenarios, such as muscle disuse in bed rest patients and its contribution to sarcopenia in the elderly, in addition to improving the sustainment of human life in space (reviewed in [20]). Indeed, muscle unloading on earth in such conditions leads to a similar atrophy as that seen in space, mainly portrayed by a pronounced, rapid decrease $(>50 \%)$ in protein synthesis rates $[21,22]$. Though the issue appears to be unsettled, there seems to be stronger evidence pointing towards the disposition of the slow type I fibers to atrophy when exposed to microgravity (reviewed in [20]). Indeed, it was shown that postural muscles, which contain a higher percentage of slow fibers, are more susceptible to atrophy than non-postural ones $[23,24]$. In space atrophy, not only a rapid loss in muscle mass, peak force and power is detected when muscle is exposed to microgravity, but there is also further muscle fiber damage following space travel caused by gravitational loading upon the return to earth [25]. Furthermore, bone mineral density is also affected during space flight, where astronauts experience a negative calcium balance losing on average $250 \mathrm{mg} /$ day [26]. Similar to muscle atrophy, microgravity exposure also induces a reduction in bone mass, which is comparable to osteopenia, a condition where bone mass is lost as a result of disuse in bed rest patients [27]. Changes in calcium fluxes and the downstream activity of calcium-binding proteins are behind the mechanotransductive deficits causing these effects $[28,29]$.

In an attempt to stimulate specific calcium signals to regulate the cell behavior, exposure to electric fields (EFs) and magnetic fields (MF), separately or in combination have been studied extensively. Electromagnetic fields (EMFs) affect calcium efflux [30-32] and influx $[33,34]$ in numerous cellular systems, stimulating downstream calcium-dependent processes. MFs by themselves have also been shown to alter the calcium signaling system in diverse experimental models [33, 35-37]. The physical coupling between calcium signaling and EMFs could be the result of ion-protein interactions $[38,39]$ or from the effect of the induced electric currents in the signaling [40]. Many authors propose that calcium itself as an ion is the primary target of EMFs during the initial step of coupling [41-44]. In addition, other forms of stimulation where calcium provokes the activation of downstream signaling 


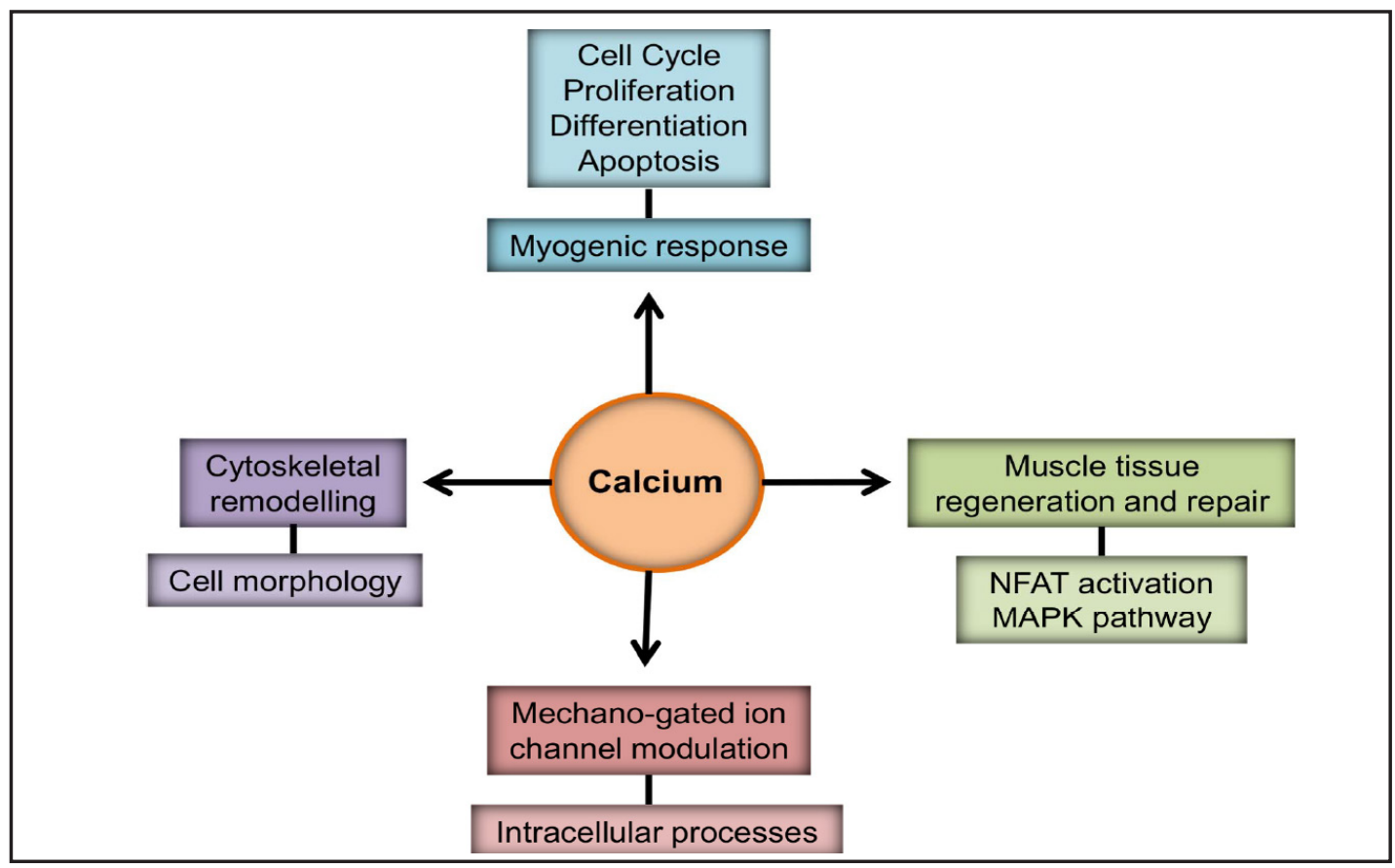

Fig. 1. Calcium regulation of cellular processes. The myogenic responses consist of changes in cell cycle, proliferation, differentiation, and apoptosis. The cytoskeletal remodeling alters the cellular morphology. The modulation of mechano-gated ion channels regulates downstream intracellular processes. The multiple pathways which are necessary for muscle tissue regeneration and repair include the nuclear factor of activated T cells (NFAT) and the mitogen-activated protein kinase (MAPK) family.

pathways include exercise in the form of muscle stretch $[45,46]$ and shear stress through fluid flow $[47,48]$.

\section{Calcium regulation}

Calcium plays a crucial role in the translation of physical forces to cellular signals through a mechanism involving changes in its cytosolic concentration. For instance, the opening frequency of membrane channels, which alters the reaction rate of calcium transportation into the cell, regulates calcium-dependent downstream signaling pathways as a response [49-52]. In this review, the calcium mediated responses, which cause a series of effects in cellular homeostasis in muscle, will be discussed (see Fig. 1). Such include the myogenic responses through changes in cell cycle, proliferation, differentiation and apoptosis; the cytoskeletal remodeling altering the cellular morphology; the modulation of mechano-gated ion channels and downstream intracellular processes; and the multiple pathways which are necessary for muscle tissue regeneration and repair, consisting of the expression of the nuclear factor of activated T cells (NFAT), as well as the activation of mitogen-activated protein kinase (MAPK).

Intracellular calcium concentration regulates signaling mechanisms that control various biological processes crucial in the development and regeneration of an organism. Depending on the calcium signal, which is unique in a spatiotemporal pattern, responses can range from short term effects such as gene transcription, signal transduction, contraction and secretion, to longer term regulation of fertilization, proliferation, migration, differentiation, apoptosis, and necrosis $[53,54]$. In particular, a localized transient change in calcium concentration controls cell migration and muscle contraction, while a prolonged global calcium signal regulates diverse biological processes such as fertilization and apoptosis [54, 55]. Not all responses are positive for cell survival, as calcium can be highly toxic when its normal concentration is exceeded. A continuous increase in calcium concentration could lead to 


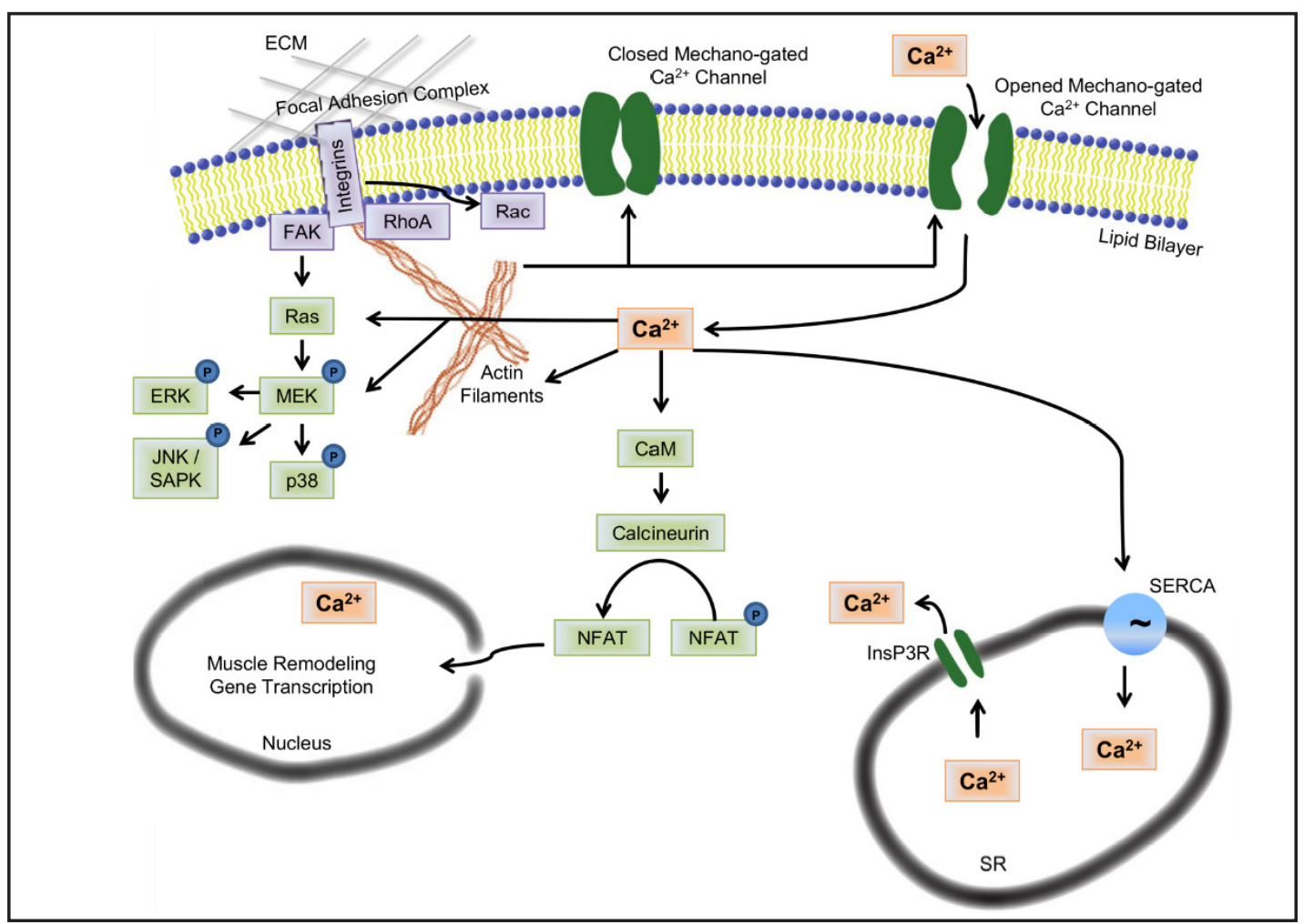

Fig. 2. Calcium-dependent cellular responses. In muscle, the internal stores are held by the sarcoplasmic reticulum (SR), where calcium release is controlled mainly by the inositol-1,4,5-trisphosphate receptor (InsP3R) and its return is governed by the sarco-endoplasmic reticulum ATPase (SERCA) pumps. Calcium binds to calmodulin (CaM) in the cytoplasm and activates calcineurin, which dephosphorylates nuclear factor of activated T cells (NFAT) and induces its translocation into the nucleus, where it initiates muscle remodeling gene transcription. The mitogen-activated protein kinase (MAPK) pathway is activated through extracellular ligands and intracellular calcium. It consists of the mitogen-activated protein kinase (MEK), phosphorylated by Ras, which in turn phosphorylates the downstream MAPK subfamilies: the extracellular signal-regulated kinases (ERKs), c-Jun NH2-terminal protein kinases (JNKs) or stress-activated protein kinases (SAPKs), and p38 MAPKs. Focal adhesions are composed of protein complexes such as integrins and focal adhesion kinases (FAKs), which link the cytoskeleton to the extracellular matrix (ECM). Actin, a protein that forms microfilaments, is part of the cytoskeletal scaffold that influences calcium channel activity and in turn its assembly is calcium-dependent. The Rho family of small G proteins, consisting of Rac and RhoA, control the cytoskeletal reorganization by regulating the actin metabolism.

cellular damage by the activation of proteases and the augmented production of reactive oxygen species (reviewed in [56]). It is therefore essential that calcium homeostasis is maintained to ensure proper cellular function.

In muscle cells, the discreet events describing the transient release of calcium from the sarcoplasmic reticulum (SR) are known as calcium sparks. These localized signals are defined by an increase from the basal levels of the intracellular calcium concentration in well-defined subcellular spaces. In muscle fibers, calcium sparks are induced by diverse stimuli. When stressing muscle fibers by osmotic shock, it has been shown that the calcium transients are reversible, repeatable, and highly localized in the fiber edge close to the sarcolemmal membrane [57]. The transient events are inhibited in contrast during resting conditions under normal physiological circumstances [58]. The nature of the calcium signal, being a rapid transient event or a prolonged global incident, appears to be dependent on the 
intensity of the stimulus. When the stimulus is strong enough a certain threshold is reached, and the transient signal is sustained initiating a global calcium wave at a cellular level [59].

Cytosolic calcium concentration is mainly increased by the rapid, transient release of ions from intracellular stores or by the slow entry of calcium from the extracellular pool into the cell by membrane channels (reviewed in [60], see also Fig. 2). The internal stores are held by the endoplasmic reticulum (ER), or the SR in muscle cells. These stores are activated by calcium itself, where its release is controlled mainly by the inositol-1,4,5-trisphosphate receptor (InsP3R) and the ryanodine receptor (RYR), while its return is governed by the sarco-endoplasmic reticulum ATPase (SERCA) pumps, as illustrated in the right side of Figure 2. Furthermore, the mitochondria also sequester and release calcium, serving as additional reservoirs (reviewed in [54]). Calcium itself plays a key role in its own regulatory mechanism, by controlling its own sensitivity, modulating ion channels, refilling the intracellular calcium stores, and regulating the process of its own sequestration and extrusion (reviewed in [61]). The dynamics of the calcium transients resulting from the internal stores are different, depending on the receptor from which calcium is released. The RYR-mediated signal occurs rapidly (in less than one second), whereas the delayed long-lasting calcium signal mediated by InsP3R ranges in the order of seconds to minutes [62, 63].

Through the activation of phospholipase C (PLC), membrane receptors like G proteincoupled receptors and tyrosine kinase receptors generate two second messengers, inositol1,4,5-trisphosphate (InsP3) and diacylglycerol (DAG). DAG works in the cell membrane and activates the protein kinase C (PKC), whereas InsP3 interacts with the InsP3Rs on the ER, raising the intracellular calcium concentration by inducing its release from the stores and initiating a calcium signal within the cell $[64,65]$. As a result of depleting the calcium stores from the ER, a signal is sent to the plasma membrane and the store-operated channels (SOCs) are slowly activated, allowing capacitative calcium entry (CCE) or store-operated calcium entry into the cells [66-68]. Calcium influx through these channels serves to mediate longer term intracellular calcium increases and to replenish the intracellular stores $[66,67]$.

SAC activity is influenced by the lipid composition of the cellular membrane and the interaction between the cytoskeleton and the ECM. Indeed, SACs can change their conformation to open and close in response to the mechanical properties of the lipid bilayer in which they are inserted, converting membrane stretch into ion current and biochemical signals (reviewed in [69]). The existence of SACs has been shown in many cell types, including muscle cells [70-72]. SAC activity is common in neonatal skeletal muscle tissue and undifferentiated myoblasts, where an increase in calcium influx is provided for myoblast maturation, and then SAC expression declines as myoblasts differentiate and fuse into myotubes $[73,74]$.

Calcium ions serve different functions inside a cell. Besides controlling most of the mechanisms implicated in muscle development and regeneration, calcium is required in the proper functioning of smooth muscles cells, maintaining arteriolar tone [75], and myogenic constriction [76]. In skeletal muscle, contraction requires transient increases in intracellular calcium concentration [77]. The purpose of this review is to discuss the relevance of calcium entry, signaling and downstream responses to mechanical forces during muscle development, repair, and regeneration. The key mechanosensitive pathways that impart these effects and control muscle growth and repair will therefore be described along with examples of diverse mechanical stimuli which regulate their activity.

\section{Myogenic responses: cell cycle, proliferation, differentiation, and apoptosis}

Changes in calcium influx initiate a variety of signaling cascades required for cell growth and division, as calcium is required at different stages of the cell cycle (reviewed in [78]). The signaling involves receptors, channels, transducers, effectors, enzymes, pumps, and exchangers, all of which are sensitive to calcium (reviewed in [79]). 
Cell Cycle

One of the calcium-sensitive proteins that decode cytosolic calcium signals is calmodulin $(\mathrm{CaM})$, as shown in Figure 2. The interaction between calcium and CaM is necessary in many cellular processes. In the cell cycle, this interaction is involved during the reentry from G0, at the G1 checkpoint, in the G1/S and the G2/M transitions, during M phase progression and at exit from mitosis (reviewed in [78]). Specifically during mitosis, calcium and CaM are necessary for nuclear envelope breakdown, cytokinesis and the regulation of the actomyosin contractile ring [80]. This is supported by experiments in where CaM expression was constitutively increased causing the cell morphology to become flattened while differences in the organization of microtubules were observed and the cell cycle progression was altered [81]. In agreement, changes in intracellular calcium concentration have been described during G1, S phase, and mitosis, including at the metaphase/anaphase transition and during cytokinesis, corresponding to the same cell cycle points where the interaction between calcium and CaM is required (reviewed in [82]). Intracellular levels of CaM are also regulated during the cell cycle, as well as downstream protein kinases, like the CaM-kinase II (CaMKII) which is dependent on CaM activation. Indeed, along with calcium and CaM, CaMKII also mediates the G1/S, G2/M and the metaphase/anaphase transitions (reviewed in [82]).

Cell cycle progression, which marks the proliferation rate, is dependent on extracellular calcium influx into the cell. When extracellular calcium is depleted, both mouse and human fibroblasts accumulate in G1 in a reversible manner, as cells continue to proliferate when normal calcium concentrations are restored (reviewed in [78]). Calcium influx through permeable calcium channels, contribute to the turning of the cell cycle. Depending on the specific channel, depletion can induce cell cycle arrest in the G0/G1 state [83] or regulate the G2/M phase progression [84]. As well as the dependence on extracellular calcium, intracellular calcium stores also control cell cycle progression. As it has been described previously, changes in cytoplasmic calcium concentration are generated not only by calcium influx from the extracellular environment through the calcium channels at the cell membrane, but also by the release of calcium from the intracellular stores. In concurrence, depletion of InsP3 stores causes an arrest in cell proliferation through inhibition of DNA and protein synthesis and accumulation of cells at the G0 state in muscle cells [85].

Mechanical forces can alter calcium concentration, impacting downstream signaling pathways that affect the cell cycle progression. In skeletal muscle, we reported a hindrance in cell proliferation in mechanically unloaded C2C12 myoblasts cultured under simulated microgravity on the random positioning machine (RPM) [86]. We discovered that the slow cell growth was due to a delay in the G2/M phase exit, where cells accumulated specifically between the G2 checkpoint and the onset of anaphase [87]. In this study, we have also shown that hypergravity at $4 \mathrm{~g}$ does not affect myoblast proliferation or cell cycle progression. Furthermore, by using a novel RPM that simulates partial gravity, we observed a linear correlation between the slowed cell growth and the accumulation in the G2/M phase corresponding to the partial gravity level of exposure [88]. We attribute these effects to an impaired regulation of calcium through mechanosensitive channels disturbed by the removal of the force of gravity.

As well as having a direct influence on cell cycle progression, calcium also regulates indirect mechanisms such as the activation of proteases that are in charge of degrading cyclins, which are crucial in the turning of the cell cycle (reviewed in [82]). In addition, calcium is also involved in centrosome duplication [89], cellular adhesion to the extracellular matrix needed through the G1 checkpoint $[90,91]$, and integrin organization required both at G0/G1 and in mid-late G1 states [92].

\section{Proliferation}

A lot of time has passed since it was first suggested that in the C2 mouse myogenic cell line, calcium entry through mechanosensitive channels is involved during the early stages of myogenesis by mediating cellular activities through calcium-sensitive molecules necessary for cell proliferation [93]. When extracellular calcium concentration is lowered, calcium entry 
into the cell is mitigated, leading to a decrease in cell proliferation [94]. Hormones, growth factors, cytokines, and other proteins regulate, and are regulated by, calcium homeostasis as calcium is as a messenger that acts directly on target proteins, or indirectly through calcium binding proteins. Calcium elicits specific responses depending on the nature of the signal, as temporal and spatial differences give rise to different reactions (reviewed in [95]). Due to the complexity of calcium signals and the numerous calcium binding proteins, calcium is used universally by the cell in most of its functions.

\section{Differentiation}

During myogenesis, satellite stem cells proliferate as myoblasts, then withdraw from the cell cycle and start to differentiate by expressing muscle specific genes. In this subsequent process, myoblasts migrate and align with each other, finally fusing with other myoblasts to form nascent multinucleated myotubes or with preexisting myofibers. These muscle fibers undergo further maturation by increasing in size and expressing contractile proteins. In muscle atrophy, the myofiber size decreases with disuse, while in hypertrophy it increases as with augmenting the mechanical loading during exercise. The myofiber size depends on the number of nuclei in the fiber, where changes promote an alteration in the contractile strength of the muscle. For instance, the loss of nuclei due to mechanical unloading causes muscle atrophy, while an increase in nuclei is related to hypertrophy and recovery from atrophy $[96,97]$.

Calcium not only plays a major role in myogenesis by influencing proliferation through the cell cycle progression, but it also controls differentiation. In the initial phase of differentiation, calcium activates several myogenic transcription factors such as myogenin and myocyte enhancer factor-2 (MEF2), which then trigger the expression of muscle specific genes (reviewed in [98]). Furthermore, myoblast recognition, adhesion, alignment, as well as membrane union required for fusion are calcium-dependent processes (reviewed in [99]). The role of calcium in myoblast fusion was originally identified in a report where fusion was reversibly inhibited when the extracellular calcium concentration was depleted, and restored when the concentration was increased [100]. Other studies have consistently revealed that pharmacological blockade of the calcium channels inhibited myoblast fusion $[101,102]$. However, calcium entry through these channels is not the only requirement for fusion as the internal stores are also needed to regulate the changes in intracellular calcium concentration. Indeed, when drugs were used to deplete these stores, fusion was inhibited [101]. Thus, the role of calcium in myoblast fusion is both intra- and extracellular and specific of calcium per se, as other ions cannot substitute its depletion (reviewed in [99]). In addition, the activation of calcium sensors such as CaM, is essential for propagating the calcium signaling required for myoblast fusion [103].

For differentiation to proceed, migration is required to allow myoblast alignment and subsequent fusion into myotubes. This process involves the activation of calpains, which are cysteine proteases activated by calcium, and the subsequent proteolysis of myristoylated alanine-rich C-kinase substrate (MARCKS), which is an actin-binding protein [104]. Indeed, the expression of calpastatin, a specific inhibitor of calpains, is decreased in fusing myoblasts [105], and when calpain activity is blocked, so is muscle differentiation [106]. It has been suggested that membrane fusion by the action of calpains results from the destabilization of the cellular membrane caused by the degradation of cytoskeletal proteins [107]. Indeed, by mechanically stimulating C2C12 mouse myoblasts with magnetic beads, calpain expression was augmented and followed by a breakdown of focal adhesion proteins [108]. In line with this argument, a significant increase in calpain activity can lead to muscle atrophy, as it triggers protein degradation [109]. Also in C2C12 myoblasts, it was reported that a transient overexpression of calcium channels concomitant with an increase of calcium influx and of calpain activity is needed for cell differentiation [110]. In agreement, we detected that a decreased expression of the same channel inhibits terminal differentiation in C2C12 myoblasts cultured on the RPM [86]. In their maturation process, it has also been shown that C2C12 myoblasts undergo cytoskeletal remodeling through the formation of stress fibers, 
where their contraction generates mechanical tension in the cell membrane and activates SACs, triggering calcium-dependent signals necessary for terminal differentiation [73].

\section{Apoptosis}

In addition to controlling cell growth and differentiation, calcium also regulates cell death through apoptosis (reviewed in [111]). Intracellular calcium signals trigger apoptosis through the Fas system (reviewed in [54]), via calcineurin that is involved in the dephosphorylation of Bad and its translocation to the mitochondria [112], and through calpains (reviewed in [111]) that are implicated in the cell spreading and mobility [113]. By mediating calcium influx, it has been shown that calcium channels regulate calpain activity in a process involving cell adhesion [114]. In this study, over-expression of the channels led to cell detachment and death probably due to the toxicity caused by calcium overload. Indeed, cells undergoing apoptosis experience an increase in intracellular calcium due to the emptying of the internal stores as well as an augmented influx from the extracellular medium [115]. Interestingly, while EMFs can protect cells by inhibiting induced apoptosis via calcium modulation through a mechanism involving enhanced calcium influx, due to an increase in the number of calcium channels in the cell membrane [116], the rise of intracellular calcium during apoptosis can also result in cell death [36, 37].

The responses downstream of mechanical stimulation are complex, but they often implicate calcium. Depending on the signal generated, the outcome can vary leading to differences in viability, cell cycle progression, growth and differentiation. In skeletal muscle, these results affect the myogenic program responsible for normal development, and thus alterations may originate abnormalities due to the implied deficits in mechanotransduction.

\section{Cytoskeletal remodeling: cell morphology}

Mechanical stimuli are known to regulate cell morphology and function [117]. As cells sense their extracellular environment, the forces acting at the level of the cellular membrane are distributed to the cytoskeleton through a mechanism associated with calcium signaling [118]. In return, the response of the cytoskeleton to membrane tension involves an increase in calcium influx through SACs, possibly by altering the properties of the lipid bilayer leading to the subsequent activation of calcium channels [119]. Indeed, the cytoskeleton is involved in regulating the activity of mechanosensitive ion channels by shifting their opening and closing states in response to mechanical stress $[118,119]$. Furthermore, when the connection between the cytoskeleton and the plasma membrane is disturbed, the channel sensitivity is also affected [120].

Embedded within the lipid bilayer linking the plasma membrane to the cytoskeleton and the ECM are the focal adhesions. Focal adhesions are composed of protein complexes, such as integrins, talin, paxillin, and focal adhesion kinases (FAKs) (reviewed in [3], see purple boxes in Fig. 2). It has been proposed that these proteins could serve as mechanosensors, initiating key signaling events in mechanotransduction, which entails the ability of cells to sense and respond to the extracellular environment by modulating the force generated through such complexes and linking it to the cytoskeleton [121]. In order to achieve cell spreading and migration, the focal adhesions must be constantly adapted. Integrins, which are transmembrane adhesion receptors, mediate the generation of force necessary for cell adhesion and motility on the ECM (reviewed in [122]). They activate intracellular molecules, such as FAKs, to regulate the signals transduced across the cell membrane (reviewed in [123, 124]).

\section{Mechanical stress and strain on the cytoskeleton}

In embryonic muscle cells, mechanical stress at the cell surface induced by magnetic microbeads promoted an increase of FAK phosphorylation [117]. It has been suggested that the activation of FAK leads to an increase in myogenic regulatory factors, which promote 
differentiation [125] regulated by calcium-dependent proteases [108]. In addition, it has been shown that voltage-gated calcium channels, which are critical for myoblast differentiation, are modulated by integrins [126]. Thus, integrins play a major role in regulating calcium influx, influencing the mechanotransduction process associated with muscle development. The force mediated by integrins is regulated by the tyrosine kinase Src [127], which is reciprocally activated in a calcium-dependent manner during stretch [128].

The cytoskeletal structures, such as actin and microtubules, are essential in triggering a variety of transduction pathways in response to mechanical stimuli by distributing the sensed forces throughout the cytoskeleton (reviewed in [129]). Actin, a calcium-sensitive protein that forms microfilaments, provides the cytoskeleton a scaffold to withstand physical stress [130]. When mechanical forces are applied to the actin network, the cell stiffness is modified [131]. It has been reported that the application of force through collagen-magnetic beads to integrins provokes calcium influx as well as calcium-dependent actin reorganization [130]. In this report, the collagen-beads were bound to cells and the role of calcium in the regulation of force-mediated actin assembly and membrane stiffness was determined. Under the stimulation, it was shown that actin filaments accumulated in the submembrane cortex and that membrane rigidity increased as well as calcium influx. The authors concluded that actin assembly induced by mechanical forces is dependent on calcium and that actin in turn influences calcium signaling by modulating SAC activity, as illustrated in Figure 2. Interestingly, after repeated stimulation, the calcium response was progressively attenuated over time, showing a protective effect for cells exposed to chronic mechanical forces, where the homeostasis of calcium-dependent signaling processes is preserved. This regulatory mechanism is essential for cell survival, as a prolonged rise in cytoplasmic calcium induces apoptosis [132].

Cadherins are transmembrane proteins that function as receptors regulating cell-cell adhesion through a calcium-dependent process. Of special interest is N-cadherin, which is essential for muscle differentiation. The Rho family of small G proteins, consisting of Rac and RhoA, control the cytoskeletal reorganization by coordinating the formation and maintenance of the cadherin-dependent adhesion sites as well as regulating the actin metabolism (reviewed in [133], see also Fig. 2). In C2C12 myoblasts, the formation of cellcell contacts by N-cadherin is dependent on the activity of Rac and RhoA [134]. While Rac is not entirely necessary for contact formation, RhoA is required as it stabilizes $\mathrm{N}$-cadherin at the cell-cell adhesion sites. This is because on the one hand, RhoA controls the formation of actin filaments bound to the cell membrane by adhesion complexes, and on the other hand, Rac is responsible for the formation of tightly packed actin filaments that are linked to the membrane by focal complexes, not directly influencing cell-cell adhesion sites but still facilitating their formation [135]. In another line of research, both Rac and RhoA were shown to influence activation of members from the MAPK family in response to mechanical strain [136]. It was proposed by the authors, that the contribution of Rac and RhoA in this activation is associated to their function in regulating the cytoskeletal organization, and not directly linked to the signaling cascade in the MAPK pathway.

\section{Other stimuli on the cytoskeleton: magnetic fields and gravitational loading}

MFs promote cell shape modifications comprising of changes at the cellular surface and in the intracellular cytoskeleton. Depending on the field strength, the exposure time and the cell type being analyzed, cells may experience partial detachment or a stronger adhesion to the surface where they are growing, resulting in an altered morphology going from round to a flat shape. Calcium-dependent signaling, influenced by MFs, has been shown to induce changes in cell morphology, including cell shape modifications and changes in microtubular reorganization [137]. As the polymerization of actin is a calcium-dependent process, changes in calcium homeostasis due to MF exposure lead to the reorganization of the cytoskeleton [138].

Gravitational force also alters the cytoskeletal integrity, thereby affecting cellular functions such as the transportation of organelles, cell maintenance, division and apoptosis. 
Indeed, after exposure to microgravity, cytoskeletal and mitochondria abnormalities were reported as a result of microtubular disruption [139]. Microtubules, like actin filaments, are involved in maintaining cell structure, in addition to providing intracellular transport of proteins and mitochondria. The polymerization of microtubules is a calcium-dependent process affected by gravitational forces [140]. Thus changes in calcium, due to environmental factors such as gravity, account for a chain of molecular responses from the cell surface to the cytoskeleton. Not only microgravity, but also mechanically overloading the cells with hypergravity, causes a change in the microtubules. Indeed, an increase in phosphorylation of microtubule-associated proteins was detected in human cells exposed to $35 \mathrm{~g}$ [141]. In addition, FAK activity is also altered by gravity, as phosphorylation of FAK decreased in humans exposed to mechanical unloading [142]. The changes in FAK activation led to downstream signaling alterations such as disturbances on the MAPK pathway, which is essential for cell growth and differentiation (reviewed in [143]). Consequently, reciprocal changes in calcium homeostasis and the cytoskeletal dynamics play a substantial role in determining the muscle tissue fate in response to mechanical stimuli.

\section{Mechano-gated ion channel modulation: converting mechanical signals into calcium-mediated intracellular processes}

Mechano-gated calcium channels are expressed abundantly in muscle at all stages of development, playing a key physiological role in cardiac, skeletal, and smooth muscle cells [144-146]. Of particular interest, are the transient receptor potential (TRP) channels which are ion channels that participate in the mechanotransduction of a wide variety of organisms, tissues and cell types, including skeletal muscle (reviewed in [147]). The TRP family is divided into various subfamilies, many of which have been described as calcium permeable channels, including: TRP canonical (TRPC), TRP melastatin (TRPM), TRP polycystic (TRPP), and TRP vanilloid (TRPV) [148]. TRP channels have been shown to be sensitive to various forms of mechanical forces, including fluid shear stress and membrane stretch, in addition to controlling vascular smooth muscle contraction and relaxation, and interacting with external ligands and cellular proteins (reviewed in $[149,150])$. In fact, these channels mediate responses to light, growth factors, pheromones, olfaction, temperature, $\mathrm{pH}$, osmolarity, vasorelaxation of blood vessels, metabolic stress, as well as other mechanical and biochemical signals [150].

\section{Faulty channel regulation leads to disease}

Mutations in TRP channel proteins have been linked to several diseases, such as cancer and neurodegenerative disorders [150]. Indeed, TRP channels, being mechanosensitive SACs, have been implied in the alteration of calcium regulation observed in muscle diseases such as $m d x$ mouse and human Duchenne dystrophies, stretch-induced muscle damage, and cardiac hypertrophy $[151,152]$. Duchenne muscular dystrophy (DMD) is a disorder affecting muscle development caused by a mutation in the dystrophin gene. Dystrophin comprises a large multimeric protein complex which links the inside of the cell to its outside [153]. DMD is characterized by a loss of calcium homeostasis in muscles, where the total calcium content is largely augmented [154] due to increased channel permeability to calcium caused by an upregulation of the mechanosensitive channel activity $[155,156]$. In the dystrophic $m d x$ mouse model, membrane stretch which causes calcium channels to be in prolonged opening mode, along with the loss of the habituation of these channels were shown to contribute to the elevated calcium concentration [157]. This leads to anomalous muscle contraction, as well as damage to the cell membrane and cytoskeleton, which consequently results in the loss of muscle cells [158].

As a therapeutic possibility to reverse or prevent the loss of calcium homeostasis in skeletal muscle, the use of electromagnetic fields has been investigated. Calcium handling affected by EMFs was studied in undifferentiated C2C12 myoblasts, as well as in terminally 
differentiated myotubes [159]. The authors revealed that exposure to EMFs increased the percentage of cells with voltage-dependent calcium influx in immature myoblasts, while in mature myotubes, the cytosolic calcium concentration was elevated due to an enhanced activity of the intracellular calcium stores. These outcomes, which appear dependent on the stage of cell differentiation, are fundamental in muscle tissue repair and development as they contribute to the regulation of myogenesis.

\section{The TRPC subfamily}

In muscle, one of the most studied TRP subfamilies is TRPC. TRPC activity is regulated by calcium itself, where CaM, a soluble calcium binding and regulatory protein, is involved [160]. Calcium influx through TRPC channels control a huge variety of biological functions, including regulation of smooth muscle cell proliferation, endothelin-evoked arterial contraction, neuronal differentiation and cardiac hypertrophy (reviewed in [161]). These channels play distinct roles depending on the cell type where they are expressed, being critical in physiopathological processes like muscle dystrophy, myasthenia gravis, vascular hypertrophy, and idiopathic pulmonary arterial hypertension [162-164]. Specifically implicated in muscular mechanotransduction are the channels TRPC1 and TRPC6, which are calcium permeable channels (reviewed in [148]). It has been shown that TRPC1 is extensively expressed in the myocytes of the heart, the arteries and the skeletal muscle [165], while TRPC6 is expressed in general in all the cardiovascular system, including pulmonary artery smooth muscle cells and vascular endothelial cells $[164,166,167]$. TRPC1 is mainly upregulated as an adaptive injury response in blood vessels [168] and during myogenesis in skeletal muscle [162]. In addition, several studies have shown that both channels are involved in cardiac hypertrophy [148]. It is well-known that the heart, probably the most important muscle organ in our body, is sensitive to mechanical forces. In correlation, an increase in intracellular calcium through TRPC channels is responsible for the development of cardiac hypertrophy [169]. Besides being SOCs, both TRPC1 and TRPC6 are SACs, and upon membrane stretch they become activated and elevate the intracellular calcium concentration by a process involving a reduction in the membrane bilayer thickness which biases the channel conformation towards the open state $[84,151,162,170]$.

In a recent study, we examined the early stages of myogenesis under conditions of simulated microgravity by culturing $\mathrm{C} 2 \mathrm{C} 12$ mouse myoblasts, as an in vitro model of the skeletal muscle phenotype, on the RPM [86]. We detected a decrease in TRPC1 expression, revealing that a reduction in calcium entry thus appears to be a pivotal event in muscle atrophy. Furthermore, our results indicated that by relieving the constant force of gravity on cells one can better understand the cellular responses leading up to muscle atrophy as a consequence of mechanical unloading.

\section{Other TRP subfamilies: TRPV and TRPP}

Many TRP channels have been shown to be activated by cell swelling or stretching as a result of cell volume regulation by extracellular calcium influx [171, 172]. Cell volume regulation is critical for a wide range of cell types to function properly and survive. Other TRP channels involved in mechanosensing and translating the response into calcium signals include TRPV and TRPP channels. For instance, TRPV4 is a volume-activated, calcium permeable channel [171] and TRPP2 regulates calcium influx by detecting mechanical deflections of primary cilia in renal epithelial cells, governing downstream signaling cascades associated with cell growth and differentiation [173]. There are many different types of calcium channels within muscle cells, but importantly, it is the calcium entry through these channels and the changes in intracellular calcium concentration that regulate downstream pathways which control muscle tissue regeneration and repair. 


\section{Muscle tissue regeneration and repair: NFAT activation}

NFAT is a transcription factor that is activated by the calcium-dependent phosphatase calcineurin (reviewed in [174]). In the resting state, NFAT is usually located in the cytoplasm in a phosphorylated latent form. As illustrated in the center green boxes in Figure 2, when the intracellular calcium concentration is increased, calcium binds to the calmodulin-calcineurin complex in the cytoplasm and activates calcineurin, which dephosphorylates NFAT by removing the phosphate groups that mask its nuclear localization signal, and permits its translocation into the nucleus where its function as a transcription factor is enabled [175]. Its nuclear accumulation induces the DNA binding to target promoter elements either by itself or with the aid of other transcription factors (reviewed in [174]). Activated calcineurin also localizes to the nucleus, thereby maintaining the dephosphorylated status and nuclear localization of NFAT. As nuclear calcium decreases, calcineurin is no longer activated, so NFAT is rephosphorylated by kinases and leaves the nucleus, terminating its function as a transcription factor (reviewed in [174]). Hence, for the NFAT signaling pathway to be activated, both cytoplasmic and nuclear calcium are required [176].

NFAT, as described by the name itself, was discovered in T lymphocytes, but has now been shown to be expressed and function in numerous cellular systems, including skeletal muscle. Indeed, NFAT plays a key role in various skeletal muscle processes such as growth and development (reviewed in [177]), regulation of hypertrophy [178, 179], and remodeling by directing myofiber type transformation $[180,181]$.

\section{Effects of electrostimulation on muscle fibers and NFAT expression}

Mechanical stimulation, such as exercise training, causes an increased oxidative metabolism in skeletal muscle, inducing fiber transition from type II to type I. During the transformation, the fast myofibers change their contractile and metabolic characteristics to those attributed to the slow fibers. It has been reported that NFAT activity regulates this process by upregulating the slow MHC and downregulating the fast MHC gene expression (reviewed in [182]). When activated, NFAT maintains the slow type I while repressing the fast type II gene and protein expression (reviewed in [14]). NFAT activity is higher in slow myofibers compared to the fast fibers and by inhibiting NFAT activation, the slow MHC expression is downregulated, whereas the fast type MHC is upregulated [183]. When primary myocytes were subjected to electrostimulation, a fast to slow fiber transformation was detected through the nuclear translocation of NFAT [181]. Interestingly, in this study the resting calcium concentration remained constant, thus the authors proposed that the NFAT signaling pathway is activated by the repetition of rapid, high amplitude calcium transients instead of a sustained rise of the resting calcium concentration. Thus, in muscle transformation, this calcium signal marks the first step that leads to calcineurin activation, NFAT nuclear translocation and the switch in MHC gene expression [12].

Recent work in primary skeletal muscle cells and C2C12 cells stimulated electrically have shown that the source for NFAT activation is through extracellular calcium and its release from intracellular stores involving RYR but not InsP3R [184]. Nevertheless, the results indicated that calcineurin participates in the regulation of InsP3R expression, suggesting that NFAT activation might be involved as well in the signaling required for InsP3R synthesis. In agreement, store-operated calcium release through InsP3R has been linked to TRPC1 expression [161], which is also under control of the NFAT pathway [185].

Various molecules dependent on calcium signaling, besides NFAT, have been shown to be involved in skeletal muscle remodeling, such as MEF2 and calcineurin $[186,187]$. The calcium-dependent activation of calcineurin regulating NFAT dephosphorylation and nuclear translocation is essential in the process of fast to slow fiber type transformation. In fact, calcineurin activity, like NFAT, is needed in maintaining the slow fiber phenotype, and when inhibited, the slow contractile proteins are decreased, inducing a transformation towards the fast fiber phenotype $[180,188]$. 
The translocation of NFAT in response to electrical activity appears to require stimulation patterns similar to the ones presented in the slow fibers. A study conducted on adult mouse skeletal muscle from flexor digitorum brevis (mostly fast type fibers), revealed that electrical stimulation using activity patterns characteristic of slow fibers (at $10 \mathrm{~Hz}$ ) activated the NFAT signaling pathway, but this did not occur in response to the stimulation patterns typical of fast fibers (at $50 \mathrm{~Hz}$ ) [189]. The reason for this pattern dependency could be explained by the fast to slow fiber type transformation, as NFAT is predominantly active in the slow fibers. Thus, stimulating the fast type fibers with a pattern simulating slow fiber activity could encourage this transition. In another study, NFAT was activated by both low and high frequencies in a rat myotube model [184]. The discrepancies between these two studies may be reflected by the initial fiber type of the skeletal muscle at the point where stimulation is subjected, as well as differences in the developmental stage of the muscle which may present distinct responses to the same patterns of stimulation, and the specific NFAT isoform that is being analyzed. In fact, there appears to be four NFAT isoforms (NFATc1, NFATc2, NFATc3 and NFATc4) expressed in muscle cells, which translocate to the nucleus at specific stages of myogenesis [190]. After a rise in intracellular calcium, nuclear translocation of NFATC3 was detected only in myoblasts, whereas NFATC1 and NFATC2 were present only in myotubes [191]. Specifically, nuclear localization of NFATC2 was only observed after the initial cell fusion to form new myotubes but not in the already matured myotubes [192].

Other stimuli altering muscle fibers and NFAT expression: mechanical unloading and stretch

To investigate the effect of mechanical unloading on muscle, research on various animal models has been conducted in response to actual and simulated microgravity. Through these studies, it has been revealed that postural muscles, containing a high percentage of slow fibers, are more susceptible to atrophy under these conditions [23, 24]. In agreement with our recent findings and considering the fact that NFAT controls the expression of TRPC1 [185], we speculated that NFAT activation is reduced in myoblasts cultured under gravitational unloading, as TRPC1 expression was downregulated [86].

Another type of mechanical stimulation, passive stretch, was investigated in regards to muscle fiber transformation in differentiating C2C12 myocytes [193]. In this report, both fast and slow MHC expressions were upregulated, while no change was detected in the phosphorylation levels of NFAT and MEF2. Interestingly, a previous study in adult rabbit fibers showed that passive stretch led to muscle growth and fast to slow fiber type transformation induced by changes in intracellular calcium concentration [194]. The controversy in the apparently opposing outcomes may be settled by recognizing that the studies were conducted on different cells with diverse lengths of exposure time to passive stretch. The differentiating C2C12 cells had not formed fibers before the analysis was carried out, so it is plausible that changes in the NFAT signaling pathway cannot be detected if the fiber transition is not yet possible. Furthermore, careful interpretation must be made according to the length of stimulation, as a counter regulatory mechanism could be activated when cells are under- or overloaded.

\section{Muscle tissue regeneration and repair: MAPK pathway}

The MAPK pathway is a family of serine/threonine kinases that become activated upon tyrosine/threonine phosphorylation through diverse stimuli, including mechanical input, cytokines, growth factors, and mitogens (reviewed in [195]). As shown in the left green boxes in Figure 2, the MAPK cascade is divided in three major subfamilies: the extracellular signalregulated kinases (ERKs), c-Jun NH2-terminal protein kinases (JNKs) or stress-activated protein kinases (SAPKs), and p38 MAPKs (reviewed in [196]). All of them are activated by the phosphorylation of the mitogen-activated protein kinase kinase (MEK), which is activated 
by Ras. The MAPK pathway is involved in the regulation of cellular processes required for adhesion, cytoskeletal dynamics, growth, differentiation, and apoptosis through a mechanism often involving calcium interaction (reviewed in [197]). For instance, in skeletal muscle it has been reported that calcium influx through the activation of SACs leads to an increased activation of the ERK cascade, while inhibition of these channels inhibits ERK activity [198].

MAPK activation through stretch, stress and electrical stimulation

All three MAPK cascades (ERK, JNK, and p38) are activated by mechanical stresses such as cell stretching [199, 200] and fluid shear stress [201]. By being responsive to mechanical stimuli, MAPKs play a critical role in myogenesis [202, 203]. Exercise [204] and electrical stimulation [205] have been shown to activate the MAPK pathway in rat skeletal muscle. In C2C12 myoblasts, cyclic stretch induced proliferation while inhibiting differentiation into myotubes by increasing the phoshorylation of p38 and decreasing the phosphorylation levels of ERK [206]. In the same study, the authors reported that by inhibiting the phosphorylation of p38, the phosphorylation of ERK was increased in the stretched cells, enhancing myotube formation. In contrast, another study reported that cyclic stretch increased the phosphorylation of all three MAPK cascades, rather than only of p38, in C2C12 mouse myoblasts [207]. The difference observed in the responses, even if performed under the same kind of stretch with the same type of cells, might depend on the details of the applied stimulus, such as the magnitude and duration, as well the time of analysis, which differed in the above two studies. An additional study confirmed that both ERK and p38 are activated by mechanical stimulation [136]. In this report, mechanical strain was applied to human fibroblasts by the magnetic attraction of superparamagnetic arginine-glycine-aspartic acid (RGD)-coated beads. The authors revealed that the two small G proteins, Rac and RhoA, participated in sensing the mechanical forces that led to the modulation of ERK activity.

In addition to cellular stretch and strain, proper adhesion to the ECM is another form of mechanical stimulus that can lead to the regulation of MAPK activity. In NIH-3T3 fibroblasts, MAPK activation was obtained through cell adhesion to fibronectin, vitronectin and type IV collagen by involving cytoskeletal reorganization through integrin mediation [208]. Consistently, in DMD a disruption of the coupling between the cytoskeleton and the ECM causes abnormal activation of ERK in response to stretch [198]. In this study, a higher level of activation of ERK was detected in $m d x$ muscle fibers compared to controls upon stretch, but this was inhibited when calcium influx was attenuated by lowering the extracellular calcium concentration or blocking the calcium channels. Accordingly, it was concluded that when the mechanotransduction signaling is impaired, cell function and viability are affected resulting in muscle damage.

Other stimuli altering MAPK activation: gravity and electromagnetic fields

When cells were overloaded by hypergravity, the mechanical input enhanced ERK phosphorylation, as it was observed in primary human osteoblast-like cells in response to $13 \mathrm{~g}$ [209]. In a similar cell line, EMFs did not induce phosphorylation of ERK [210], but exposure of lens epithelial cells to EFs induced phosphorylation of ERK [211]. As MAPK activation varies greatly in response to different stimuli, there is not enough data to assess the therapeutic potential of regulating this pathway to overcome muscle deterioration. Further studies in skeletal muscle are therefore needed to define the mechanical inputs that stimulate normal and anomalous responses of the MAPK cascades.

\section{Conclusion}

The examples mentioned in this review demonstrate the relationship between calcium signaling and mechanotransduction that work together mostly through feedback mechanisms that couples cellular functions with the extracellular environment. Cellular mechanosensing and the ensuing mechanoresponse are both critical for the maintenance and regeneration 
of normal muscle development. As skeletal muscle is sensitive to mechanical input, any event that disrupts this process would result in a clinical condition, like muscle atrophy. The inability to effectively maintain muscle mass is of utmost clinical and socioeconomic importance. In order to counteract the faulty mechanism observed in such conditions, it is important to understand first how mechanical stimuli are translated to biochemical responses, and specifically identify the consequent cascade of events, mainly governed by calcium signaling. By means of model systems such as gravitational unloading to imitate muscle disuse, we gain further insights on the deregulation of the mechanotransduction signaling. And by studying the response of muscle to exercise, stretch, electric stimulation, hypergravity and EMF exposure, therapies can be developed to combat or possibly reverse the detected deregulations due to disuse, trauma, or disease. Reconciling the data gathered in the precedent experiments with ongoing and future studies will make the specific role of calcium and the contributing factors in mechanotransduction clearer in the understanding of muscle development in order to design potent countermeasures against such clinical scenarios.

\section{Abbreviations}

CaM (calmodulin); CaMKII (CaM-kinase II); CCE (capacitative calcium entry); DAG (diacylglycerol); DMD (Duchenne muscular dystrophy); ECM (extracellular matrix); EF (electric field); EMF (electromagnetic field); ER (endoplasmic reticulum); ERK (extracellular signal-regulated kinase); FAK (focal adhesion kinase); InsP3 (inositol-1,4,5-trisphosphate); InsP3R (InsP3 receptor); JNK (c-Jun NH2-terminal protein kinase); MAPK (mitogenactivated protein kinase); MARCKS (myristoylated alanine-rich C-kinase substrate); MEF2 (myocyte enhancer factor-2); MF (magnetic field); MHC (myosin heavy chain); NFAT (nuclear factor of activated T cells); PKC (protein kinase C); PLC (phospholipase C); RPM (random positioning machine); RYR (ryanodine receptor); SAC (stretch-activated ion channel); SAPK (stress-activated protein kinase); SERCA (sarco-endoplasmic reticulum ATPase); SOC (storeoperated channel); SR (sarcoplasmic reticulum); TRP (transient receptor potential); TRPC (TRP canonical); TRPM (TRP melastatin); TRPP (TRP polycystic); TRPV (TRP vanilloid).

\section{Acknowledgements}

The authors would like to thank Mr. Stéphane Richard and Dr. Fabian Ille for their insightful comments on the manuscript, Mr. Harald Dermutz for assistance with the figures, and Prof. Dr. Ralph Müller for his constant support and many fruitful discussions.

\section{References}

1 Hamill OP, Martinac B: Molecular basis of mechanotransduction in living cells. Physiol Rev 2001;81:685740.

2 Kung C: A possible unifying principle for mechanosensation. Nature 2005;436:647-654.

- J Jaalouk DE, Lammerding J: Mechanotransduction gone awry. Nat Rev Mol Cell Biol 2009;10:63-73.

4 Ingber D: How cells (might) sense microgravity. FASEB J 1999;13:S3-15.

5 Ingber DE: Tensegrity: the architectural basis of cellular mechanotransduction. Annu Rev Physiol 1997;59:575-599.

6 Traub 0, Berk BC: Laminar shear stress: mechanisms by which endothelial cells transduce an atheroprotective force. Arterioscler Thromb Vasc Biol 1998;18:677-685.

7 Zou Y, Hu Y, Metzler B, Xu Q: Signal transduction in arteriosclerosis: mechanical stress-activated MAP kinases in vascular smooth muscle cells (review). Int J Mol Med 1998;1:827-834.

8 Goldspink G: Changes in muscle mass and phenotype and the expression of autocrine and systemic growth factors by muscle in response to stretch and overload. J Anat 1999;194:323-334. 
- Jones DB, Nolte H, Scholubbers JG, Turner E, Veltel D: Biochemical signal transduction of mechanical strain in osteoblast-like cells. Biomaterials 1991;12:101-110.

10 Frost HM: Wolff's Law and bone's structural adaptations to mechanical usage: an overview for clinicians. Angle Orthod 1994;64:175-188.

11 Loughna P, Goldspink G, Goldspink DF: Effect of inactivity and passive stretch on protein turnover in phasic and postural rat muscles. J Appl Physiol 1986;61:173-179.

$>12$ Meissner JD, Kubis HP, Scheibe RJ, Gros G: Reversible $\mathrm{Ca}^{2+}$-induced fast-to-slow transition in primary skeletal muscle culture cells at the mRNA level. J Physiol 2000;523 Pt 1:19-28.

13 Goldspink G, Scutt A, Loughna PT, Wells DJ, Jaenicke T, Gerlach GF: Gene expression in skeletal muscle in response to stretch and force generation. Am J Physiol 1992;262:R356-363.

-14 Bassel-Duby R, Olson EN: Signaling pathways in skeletal muscle remodeling. Annu Rev Biochem 2006;75:19-37.

15 Schiaffino S, Reggiani C: Molecular diversity of myofibrillar proteins: gene regulation and functional significance. Physiol Rev 1996;76:371-423.

16 Parker MH, Seale P, Rudnicki MA: Looking back to the embryo: defining transcriptional networks in adult myogenesis. Nat Rev Genet 2003;4:497-507.

17 Goldspink G: Impairment of IGF-I gene splicing and MGF expression associated with muscle wasting. Int J Biochem Cell Biol 2005;37:2012-2022.

18 Bajotto G, Shimomura Y: Determinants of disuse-induced skeletal muscle atrophy: exercise and nutrition countermeasures to prevent protein loss. J Nutr Sci Vitaminol (Tokyo) 2006;52:233-247.

19 Goldspink G: Gene expression in skeletal muscle. Biochem Soc Trans 2002;30:285-290.

20 Narici MV, de Boer MD: Disuse of the musculo-skeletal system in space and on earth. Eur J Appl Physiol 2011;111:403-420.

-21 Ferrando AA, Lane HW, Stuart CA, Davis-Street J, Wolfe RR: Prolonged bed rest decreases skeletal muscle and whole body protein synthesis. Am J Physiol 1996;270:E627-633.

$22 \mathrm{Ku}$ Z, Thomason DB: Soleus muscle nascent polypeptide chain elongation slows protein synthesis rate during non-weight-bearing activity. Am J Physiol 1994;267:C115-126.

-23 Gardetto PR, Schluter JM, Fitts RH: Contractile function of single muscle fibers after hindlimb suspension. J Appl Physiol 1989;66:2739-2749.

24 Ohira Y, Yoshinaga T, Ohara M, Nonaka I, Yoshioka T, Yamashita-Goto K, Shenkman BS, Kozlovskaya IB, Roy RR, Edgerton VR: Myonuclear domain and myosin phenotype in human soleus after bed rest with or without loading. J Appl Physiol 1999;87:1776-1785.

25 Riley DA, Ellis S, Slocum GR, Sedlak FR, Bain JL, Krippendorf BB, Lehman CT, Macias MY, Thompson JL, Vijayan K, De Bruin JA: In-flight and postflight changes in skeletal muscles of SLS-1 and SLS-2 spaceflown rats. J Appl Physiol 1996;81:133-144.

26 Smith SM, Wastney ME, Morukov BV, Larina IM, Nyquist LE, Abrams SA, Taran EN, Shih CY, Nillen JL, DavisStreet JE, Rice BL, Lane HW: Calcium metabolism before, during, and after a 3-mo spaceflight: kinetic and biochemical changes. Am J Physiol 1999;277:R1-10.

27 LeBlanc A, Schneider V: Countermeasures against space flight related bone loss. Acta Astronaut 1992;27:89-92.

28 Schulte LM, Navarro J, Kandarian SC: Regulation of sarcoplasmic reticulum calcium pump gene expression by hindlimb unweighting. Am J Physiol 1993;264:C1308-1315.

29 Hunter RB, Mitchell-Felton H, Essig DA, Kandarian SC: Expression of endoplasmic reticulum stress proteins during skeletal muscle disuse atrophy. Am J Physiol Cell Physiol 2001;281:C1285-1290.

30 Blackman CF, Benane SG, House DE, Joines WT: Effects of ELF (1-120 Hz) and modulated (50 Hz) RF fields on the efflux of calcium ions from brain tissue in vitro. Bioelectromagnetics 1985;6:1-11.

31 Blackman CF, Benane SG, Kinney LS, Joines WT, House DE: Effects of ELF fields on calcium-ion efflux from brain tissue in vitro. Radiat Res 1982;92:510-520.

-32 Jolley WB, Hinshaw DB, Knierim K, Hinshaw DB: Magnetic field effects on calcium efflux and insulin secretion in isolated rabbit islets of Langerhans. Bioelectromagnetics 1983;4:103-106.

-33 Liburdy RP: Calcium signaling in lymphocytes and ELF fields. Evidence for an electric field metric and a site of interaction involving the calcium ion channel. FEBS Lett 1992;301:53-59.

34 Bourguignon GJ, Jy W, Bourguignon LY: Electric stimulation of human fibroblasts causes an increase in $\mathrm{Ca}^{2+}$ influx and the exposure of additional insulin receptors. J Cell Physiol 1989;140:379-385. 


\begin{tabular}{|c|c|c|}
\hline Cellı & Cell Physiol Biochem 2014;33:249-272 & \\
\hline and Biochemistry & $\begin{array}{l}\text { DOI: 10.1159/000356667 } \\
\text { Published online: January 31, } 2014\end{array}$ & $\begin{array}{l}\text { O } 2014 \text { S. Karger AG, Basel } \\
\text { www.karger.com/cpb }\end{array}$ \\
\hline
\end{tabular}

35 Rosen MS, Rosen AD: Magnetic field influence on paramecium motility. Life Sci 1990;46:1509-1515.

36 Fanelli C, Coppola S, Barone R, Colussi C, Gualandi G, Volpe P, Ghibelli L: Magnetic fields increase cell survival by inhibiting apoptosis via modulation of $\mathrm{Ca}^{2+}$ influx. FASEB J 1999;13:95-102.

-37 Teodori L, Gohde W, Valente MG, Tagliaferri F, Coletti D, Perniconi B, Bergamaschi A, Cerella C, Ghibelli L: Static magnetic fields affect calcium fluxes and inhibit stress-induced apoptosis in human glioblastoma cells. Cytometry 2002;49:143-149.

-38 Lednev VV: Possible mechanism for the influence of weak magnetic fields on biological systems. Bioelectromagnetics 1991;12:71-75.

39 Blanchard JP, Blackman CF: Clarification and application of an ion parametric resonance model for magnetic field interactions with biological systems. Bioelectromagnetics 1994;15:217-238.

-40 Kim YV, Conover DL, Lotz WG, Cleary SF: Electric field-induced changes in agonist-stimulated calcium fluxes of human HL-60 leukemia cells. Bioelectromagnetics 1998;19:366-376.

41 Carson JJ, Prato FS, Drost DJ, Diesbourg LD, Dixon SJ: Time-varying magnetic fields increase cytosolic free Ca2+ in HL-60 cells. Am J Physiol 1990;259:C687-692.

42 Walleczek J, Liburdy RP: Nonthermal $60 \mathrm{~Hz}$ sinusoidal magnetic-field exposure enhances 45Ca2+ uptake in rat thymocytes: dependence on mitogen activation. FEBS Lett 1990;271:157-160.

43 Barbier E, Dufy B, Veyret B: Stimulation of Ca2+ influx in rat pituitary cells under exposure to a $50 \mathrm{~Hz}$ magnetic field. Bioelectromagnetics 1996;17:303-311.

-44 Pessina GP, Aldinucci C, Palmi M, Sgaragli G, Benocci A, Meini A, Pessina F: Pulsed electromagnetic fields affect the intracellular calcium concentrations in human astrocytoma cells. Bioelectromagnetics 2001;22:503-510.

45 Riley DA, Van Dyke JM: The effects of active and passive stretching on muscle length. Phys Med Rehabil Clin N Am 2012;23:51-57, x.

46 Campbell KS: Short-range mechanical properties of skeletal and cardiac muscles. Adv Exp Med Biol 2010;682:223-246.

47 Jia X, Yang J, Song W, Li P, Wang X, Guan C, Yang L, Huang Y, Gong X, Liu M, Zheng L, Fan Y: Involvement of large conductance $\mathrm{Ca}^{2+}$-activated $\mathrm{K}^{+}$channel in laminar shear stress-induced inhibition of vascular smooth muscle cell proliferation. Pflugers Arch 2013;465:221-232.

48 Park SW, Byun D, Bae YM, Choi BH, Park SH, Kim B, Cho SI: Effects of fluid flow on voltage-dependent calcium channels in rat vascular myocytes: fluid flow as a shear stress and a source of artifacts during patch-clamp studies. Biochem Biophys Res Commun 2007;358:1021-1027.

49 Aikawa K, Nishikimi N, Sakurai T, Nimura Y, Sokabe M, Naruse K: SA channel mediates superoxide production in HUVECs. Life Sci 2001;69:1717-1724.

50 Inoh H, Ishiguro N, Sawazaki S, Amma H, Miyazu M, Iwata H, Sokabe M, Naruse K: Uni-axial cyclic stretch induces the activation of transcription factor nuclear factor kappaB in human fibroblast cells. FASEB J 2002;16:405-407.

51 Wang JG, Miyazu M, Matsushita E, Sokabe M, Naruse K: Uniaxial cyclic stretch induces focal adhesion kinase (FAK) tyrosine phosphorylation followed by mitogen-activated protein kinase (MAPK) activation. Biochem Biophys Res Commun 2001;288:356-361.

-52 Taskinen P, Ruskoaho H: Stretch-induced increase in atrial natriuretic peptide secretion is blocked by thapsigargin. Eur J Pharmacol 1996;308:295-300.

53 Berridge MJ, Bootman MD, Lipp P: Calcium--a life and death signal. Nature 1998;395:645-648.

54 Berridge MJ, Lipp P, Bootman MD: The versatility and universality of calcium signalling. Nat Rev Mol Cell Biol 2000;1:11-21.

55 Clapham DE: Calcium signaling. Cell 2007;131:1047-1058.

56 Batchelor CL, Winder SJ: Sparks, signals and shock absorbers: how dystrophin loss causes muscular dystrophy. Trends Cell Biol 2006;16:198-205.

57 Wang X, Weisleder N, Collet C, Zhou J, Chu Y, Hirata Y, Zhao X, Pan Z, Brotto M, Cheng H: Uncontrolled calcium sparks act as a dystrophic signal for mammalian skeletal muscle. Nature cell biology 2005;7:525530.

58 Weisleder N, Ma JJ: $\mathrm{Ca}^{2+}$ sparks as a plastic signal for skeletal muscle health, aging, and dystrophy. Acta Pharmacol Sin 2006;27:791-798.

59 Zhu MX, Ma J, Parrington J, Calcraft PJ, Galione A, Evans AM: Calcium signaling via two-pore channels: local or global, that is the question. Am J Physiol Cell Physiol 2010;298:C430-441. 
60 Parekh AB: Store-operated $\mathrm{Ca}^{2+}$ entry: dynamic interplay between endoplasmic reticulum, mitochondria and plasma membrane. J Physiol 2003;547:333-348.

61 Hill MA, Zou H, Potocnik SJ, Meininger GA, Davis MJ: Invited review: arteriolar smooth muscle mechanotransduction: $\mathrm{Ca}^{2+}$ signaling pathways underlying myogenic reactivity. J Appl Physiol 2001;91:973-983.

62 Eltit JM, Hidalgo J, Liberona JL, Jaimovich E: Slow calcium signals after tetanic electrical stimulation in skeletal myotubes. Biophys J 2004;86:3042-3051.

63 Jaimovich E, Reyes R, Liberona JL, Powell JA: IP(3) receptors, IP(3) transients, and nucleus-associated $\mathrm{Ca}^{2+}$ signals in cultured skeletal muscle. Am J Physiol Cell Physiol 2000;278:C998-C1010.

64 Berridge MJ, Irvine RF: Inositol trisphosphate, a novel second messenger in cellular signal transduction. Nature 1984;312:315-321.

65 Ma HT, Venkatachalam K, Li HS, Montell C, Kurosaki T, Patterson RL, Gill DL: Assessment of the role of the inositol 1,4,5-trisphosphate receptor in the activation of transient receptor potential channels and storeoperated $\mathrm{Ca}^{2+}$ entry channels. J Biol Chem 2001;276:18888-18896.

66 Putney JW Jr, Bird GS: The signal for capacitative calcium entry. Cell 1993;75:199-201.

67 Parekh AB, Penner R: Store depletion and calcium influx. Physiol Rev 1997;77:901-930.

68 Putney JW, Jr., McKay RR: Capacitative calcium entry channels. Bioessays 1999;21:38-46.

69 Sachs F, Morris CE: Mechanosensitive ion channels in nonspecialized cells. Rev Physiol Biochem Pharmacol 1998;132:1-77.

70 Davis MJ, Meininger GA, Zawieja DC: Stretch-induced increases in intracellular calcium of isolated vascular smooth muscle cells. Am J Physiol 1992;263:H1292-1299.

71 Kirber MT, Guerrero-Hernandez A, Bowman DS, Fogarty KE, Tuft RA, Singer JJ, Fay FS: Multiple pathways responsible for the stretch-induced increase in $\mathrm{Ca}^{2+}$ concentration in toad stomach smooth muscle cells. J Physiol 2000;524:3-17.

72 Kirber MT, Walsh JV Jr, Singer JJ: Stretch-activated ion channels in smooth muscle: a mechanism for the initiation of stretch-induced contraction. Pflugers Arch 1988;412:339-345.

73 Formigli L, Meacci E, Sassoli C, Squecco R, Nosi D, Chellini F, Naro F, Francini F, Zecchi-Orlandini S: Cytoskeleton/stretch-activated ion channel interaction regulates myogenic differentiation of skeletal myoblasts. J Cell Physiol 2007;211:296-306.

74 Wedhas N, Klamut HJ, Dogra C, Srivastava AK, Mohan S, Kumar A: Inhibition of mechanosensitive cation channels inhibits myogenic differentiation by suppressing the expression of myogenic regulatory factors and caspase-3 activity. FASEB J 2005;19:1986-1997.

75 Uchida E, Bohr DF: Myogenic tone in isolated perfused resistance vessels from rats. Am J Physiol 1969;216:1343-1350.

76 Narayanan J, Imig M, Roman RJ, Harder DR: Pressurization of isolated renal arteries increases inositol trisphosphate and diacylglycerol. Am J Physiol 1994;266:H1840-1845.

77 Lee EH: $\mathrm{Ca}^{2+}$ channels and skeletal muscle diseases. Prog Biophys Mol Biol 2010;103:35-43.

78 Kahl CR, Means AR: Regulation of cell cycle progression by calcium/calmodulin-dependent pathways. Endocr Rev 2003;24:719-736.

-79 Berridge MJ, Bootman MD, Roderick HL: Calcium signalling: dynamics, homeostasis and remodelling. Nat Rev Mol Cell Biol 2003;4:517-529.

80 Yu YY, Chen Y, Dai G, Chen J, Sun XM, Wen CJ, Zhao DH, Chang DC, Li CJ: The association of calmodulin with central spindle regulates the initiation of cytokinesis in HeLa cells. Int J Biochem Cell Biol 2004;36:15621572 .

81 Rasmussen CD, Means AR: Increased calmodulin affects cell morphology and mRNA levels of cytoskeletal protein genes. Cell Motil Cytoskeleton 1992;21:45-57.

82 Santella L: The role of calcium in the cell cycle: facts and hypotheses. Biochem Biophys Res Commun 1998;244:317-324.

83 Tajeddine N, Gailly P: TRPC1 protein channel is major regulator of epidermal growth factor receptor signaling. J Biol Chem 2012;287:16146-16157.

84 Ding X, He Z, Zhou K, Cheng J, Yao H, Lu D, Cai R, Jin Y, Dong B, Xu Y, Wang Y: Essential role of TRPC6 channels in G2/M phase transition and development of human glioma. J Natl Cancer Inst 2010;102:10521068.

85 Short AD, Bian J, Ghosh TK, Waldron RT, Rybak SL, Gill DL: Intracellular Ca2+ pool content is linked to control of cell growth. Proc Natl Acad Sci U S A 1993;90:4986-4990. 
86 Benavides Damm T, Richard S, Tanner S, Wyss F, Egli M, Franco-Obregon A: Calcium-dependent deceleration of the cell cycle in muscle cells by simulated microgravity. FASEB J 2013;27:20452054.

87 Benavides Damm T, Franco-Obregon A, Egli M: Gravitational force modulates G 2/M phase exit in mechanically unloaded myoblasts. Cell Cycle 2013;12:3001-3012.

-88 Benavides Damm T, Walther I, Wuest SL, Sekler J, Egli M: Cell cultivation under different gravitational loads using a novel random positioning incubator. Biotechnol Bioeng 2013;10.1002/bit.25179

-89 Matsumoto Y, Maller JL: Calcium, calmodulin, and CaMKII requirement for initiation of centrosome duplication in Xenopus egg extracts. Science 2002;295:499-502.

-90 Otsuka H, Moskowitz M: Arrest of 3T3 cells in G1 phase in suspension culture. J Cell Physiol 1975;87:213219.

-91 Guadagno TM, Ohtsubo M, Roberts JM, Assoian RK: A link between cyclin A expression and adhesiondependent cell cycle progression. Science 1993;262:1572-1575.

-92 Hansen LK, Mooney DJ, Vacanti JP, Ingber DE: Integrin binding and cell spreading on extracellular matrix act at different points in the cell cycle to promote hepatocyte growth. Mol Biol Cell 1994;5:967-975.

93 Franco A, Jr., Lansman JB: Stretch-sensitive channels in developing muscle cells from a mouse cell line. J Physiol 1990;427:361-380.

-94 Hickie RA, Wei JW, Blyth LM, Wong DY, Klaassen DJ: Cations and calmodulin in normal and neoplastic cell growth regulation. Can J Biochem Cell Biol 1983;61:934-941.

-95 Petersen OH, Petersen CC, Kasai H: Calcium and hormone action. Annu Rev Physiol 1994;56:297-319.

$\$ 96$ Allen DL, Linderman JK, Roy RR, Bigbee AJ, Grindeland RE, Mukku V, Edgerton VR: Apoptosis: a mechanism contributing to remodeling of skeletal muscle in response to hindlimb unweighting. Am J Physiol 1997;273:C579-587.

97 Mitchell PO, Pavlath GK: A muscle precursor cell-dependent pathway contributes to muscle growth after atrophy. Am J Physiol Cell Physiol 2001;281:C1706-1715.

$\$ 98$ Molkentin JD, Olson EN: Combinatorial control of muscle development by basic helix-loop-helix and MADSbox transcription factors. Proc Natl Acad Sci USA 1996;93:9366-9373.

99 Wakelam MJ: The fusion of myoblasts. Biochem J 1985;228:1-12.

100 Shainberg A, Yagil G, Yaffe D: Control of myogenesis in vitro by $\mathrm{Ca}^{2+}$ concentration in nutritional medium. Exp Cell Res 1969;58:163-167.

101 Seigneurin-Venin S, Parrish E, Marty I, Rieger F, Romey G, Villaz M, Garcia L: Involvement of the dihydropyridine receptor and internal Ca2+ stores in myoblast fusion. Exp Cell Res 1996;223:301-307.

102 Shin KS, Park JY, Ha DB, Chung CH, Kang MS: Involvement of K(Ca) channels and stretch-activated channels in calcium influx, triggering membrane fusion of chick embryonic myoblasts. Dev Biol 1996;175:14-23.

103 Bar-Sagi D, Prives J: Trifluoperazine, a calmodulin antagonist, inhibits muscle cell fusion. J Cell Biol 1983;97:1375-1380.

104 Dulong S, Goudenege S, Vuillier-Devillers K, Manenti S, Poussard S, Cottin P: Myristoylated alanine-rich C kinase substrate (MARCKS) is involved in myoblast fusion through its regulation by protein kinase Calpha and calpain proteolytic cleavage. Biochem J 2004;382:1015-1023.

105 Barnoy S, Glasner T, Kosower NS: The role of calpastatin (the specific calpain inhibitor) in myoblast differentiation and fusion. Biochem Biophys Res Commun 1996;220:933-938.

106 Dedieu S, Poussard S, Mazeres G, Grise F, Dargelos E, Cottin P, Brustis JJ: Myoblast migration is regulated by calpain through its involvement in cell attachment and cytoskeletal organization. Exp Cell Res 2004;292:187-200.

107 Dourdin N, Brustis JJ, Balcerzak D, Elamrani N, Poussard S, Cottin P, Ducastaing A: Myoblast fusion requires fibronectin degradation by exteriorized m-calpain. Exp Cell Res 1997;235:385-394.

108 Grossi A, Karlsson AH, Lawson MA: Mechanical stimulation of C2C12 cells increases m-calpain expression, focal adhesion plaque protein degradation. Cell Biol Int 2008;32:615-622.

109 Taillandier D, Aurousseau E, Meynial-Denis D, Bechet D, Ferrara M, Cottin P, Ducastaing A, Bigard X, Guezennec CY, Schmid HP, et al.: Coordinate activation of lysosomal, $\mathrm{Ca}^{2+}$-activated and ATP-ubiquitindependent proteinases in the unweighted rat soleus muscle. Biochem J 1996;316:65-72.

110 Louis M, Zanou N, Van Schoor M, Gailly P: TRPC1 regulates skeletal myoblast migration and differentiation. J Cell Sci 2008;121:3951-3959.

111 Orrenius S, Zhivotovsky B, Nicotera P: Regulation of cell death: the calcium-apoptosis link. Nat Rev Mol Cell Biol 2003;4:552-565. 
112 Wang HG, Pathan N, Ethell IM, Krajewski S, Yamaguchi Y, Shibasaki F, McKeon F, Bobo T, Franke TF, Reed JC: Ca2+-induced apoptosis through calcineurin dephosphorylation of BAD. Science 1999;284:339-343.

113 Glading A, Lauffenburger DA, Wells A: Cutting to the chase: calpain proteases in cell motility. Trends Cell Biol 2002;12:46-54.

114 Su LT, Agapito MA, Li M, Simonson WT, Huttenlocher A, Habas R, Yue L, Runnels LW: TRPM7 regulates cell adhesion by controlling the calcium-dependent protease calpain. J Biol Chem 2006;281:11260-11270.

115 Bian X, Hughes FM Jr, Huang Y, Cidlowski JA, Putney JW, Jr.: Roles of cytoplasmic Ca2+ and intracellular Ca ${ }^{2+}$ stores in induction and suppression of apoptosis in S49 cells. Am J Physiol 1997;272:C1241-1249.

116 Grassi C, D’Ascenzo M, Torsello A, Martinotti G, Wolf F, Cittadini A, Azzena GB: Effects of $50 \mathrm{~Hz}$ electromagnetic fields on voltage-gated $\mathrm{Ca}^{2+}$ channels and their role in modulation of neuroendocrine cell proliferation and death. Cell Calcium 2004;35:307-315.

117 Grossi A, Lametsch R, Karlsson AH, Lawson MA: Mechanical stimuli on C2C12 myoblasts affect myoblast differentiation, focal adhesion kinase phosphorylation and galectin-1 expression: a proteomic approach. Cell Biol Int 2011;35:579-586.

118 Sachs F: Mechanical transduction in biological systems. Crit Rev Biomed Eng 1988;16:141-169.

119 Glogauer M, Ferrier J, McCulloch CA: Magnetic fields applied to collagen-coated ferric oxide beads induce stretch-activated $\mathrm{Ca}^{2+}$ flux in fibroblasts. Am J Physiol 1995;269:C1093-1104.

120 Hamill OP, McBride DW Jr: Rapid adaptation of single mechanosensitive channels in Xenopus oocytes. Proc Natl Acad Sci U S A 1992;89:7462-7466.

121 Maniotis AJ, Chen CS, Ingber DE: Demonstration of mechanical connections between integrins, cytoskeletal filaments, and nucleoplasm that stabilize nuclear structure. Proc Natl Acad Sci USA 1997;94:849-854.

122 Hynes RO: Integrins: versatility, modulation, and signaling in cell adhesion. Cell 1992;69:11-25.

123 Schaller MD: Biochemical signals and biological responses elicited by the focal adhesion kinase. Biochim Biophys Acta 2001;1540:1-21.

124 Schlaepfer DD, Mitra SK, Ilic D: Control of motile and invasive cell phenotypes by focal adhesion kinase. Biochim Biophys Acta 2004;1692:77-102.

125 Clemente CF, Corat MA, Saad ST, Franchini KG: Differentiation of C2C12 myoblasts is critically regulated by FAK signaling. Am J Physiol Regul Integr Comp Physiol 2005;289:R862-870.

126 Wu X, Mogford JE, Platts SH, Davis GE, Meininger GA, Davis MJ: Modulation of calcium current in arteriolar smooth muscle by alphav beta3 and alpha5 beta1 integrin ligands. J Cell Biol 1998;143:241-252.

127 Felsenfeld DP, Schwartzberg PL, Venegas A, Tse R, Sheetz MP: Selective regulation of integrin--cytoskeleton interactions by the tyrosine kinase Src. Nat Cell Biol 1999;1:200-206.

128 Sokabe M, Naruse K, Sai S, Yamada T, Kawakami K, Inoue M, Murase K, Miyazu M: Mechanotransduction and intracellular signaling mechanisms of stretch-induced remodeling in endothelial cells. Heart Vessels 1997; 12: S191-193.

129 Chicurel ME, Chen CS, Ingber DE: Cellular control lies in the balance of forces. Curr Opin Cell Biol 1998;10:232-239.

130 Glogauer M, Arora P, Yao G, Sokholov I, Ferrier J, McCulloch CA: Calcium ions and tyrosine phosphorylation interact coordinately with actin to regulate cytoprotective responses to stretching. J Cell Sci 1997;110:1121.

131 Choquet D, Felsenfeld DP, Sheetz MP: Extracellular matrix rigidity causes strengthening of integrincytoskeleton linkages. Cell 1997;88:39-48.

132 Clapham DE: Calcium signaling. Cell 1995;80:259-268.

133 Hall A: Small GTP-binding proteins and the regulation of the actin cytoskeleton. Annu Rev Cell Biol 1994;10:31-54.

134 Comunale F, Causeret M, Favard C, Cau J, Taulet N, Charrasse S, Gauthier-Rouviere C: Rac1 and RhoA GTPases have antagonistic functions during N-cadherin-dependent cell-cell contact formation in C2C12 myoblasts. Biol Cell 2007;99:503-517.

135 Nobes CD, Hall A: Rho, rac, and cdc42 GTPases regulate the assembly of multimolecular focal complexes associated with actin stress fibers, lamellipodia, and filopodia. Cell 1995;81:53-62.

136 Laboureau J, Dubertret L, Lebreton-De Coster C, Coulomb B: ERK activation by mechanical strain is regulated by the small G proteins rac-1 and rhoA. Exp Dermatol 2004;13:70-77.

137 Albertini MC, Accorsi A, Citterio B, Burattini S, Piacentini MP, Uguccioni F, Piatti E: Morphological and biochemical modifications induced by a static magnetic field on Fusarium culmorum. Biochimie 2003;85:963-970. 
138 Santoro N, Lisi A, Pozzi D, Pasquali E, Serafino A, Grimaldi S: Effect of extremely low frequency (ELF) magnetic field exposure on morphological and biophysical properties of human lymphoid cell line (Raji). Biochim Biophys Acta 1997;1357:281-290.

139 Schatten H, Lewis ML, Chakrabarti A: Spaceflight and clinorotation cause cytoskeleton and mitochondria changes and increases in apoptosis in cultured cells. Acta Astronaut 2001;49:399-418.

140 Papaseit C, Pochon N, Tabony J: Microtubule self-organization is gravity-dependent. Proc Natl Acad Sci USA 2000;97:8364-8368.

141 Kumei Y, Whitson PA, Sato A, Cintron NM: Hypergravity signal transduction in HeLa cells with concomitant phosphorylation of proteins immunoprecipitated with anti-microtubule-associated protein antibodies. Exp Cell Res 1991;192:492-496.

142 de Boer MD, Selby A, Atherton P, Smith K, Seynnes OR, Maganaris CN, Maffulli N, Movin T, Narici MV, Rennie MJ: The temporal responses of protein synthesis, gene expression and cell signalling in human quadriceps muscle and patellar tendon to disuse. J Physiol 2007;585:241-251.

143 Boudreau NJ, Jones PL: Extracellular matrix and integrin signalling: the shape of things to come. Biochem J 1999;339:481-488.

144 Kraichely RE, Farrugia G: Mechanosensitive ion channels in interstitial cells of Cajal and smooth muscle of the gastrointestinal tract. Neurogastroenterol Motil 2007;19:245-252.

145 Inoue R, Jian Z, Kawarabayashi Y: Mechanosensitive TRP channels in cardiovascular pathophysiology. Pharmacol Ther 2009;123:371-385.

146 Franco A, Lansman JB: Calcium entry through stretch-inactivated ion channels in mdx myotubes. 1990;344:670-673.

147 Christensen AP, Corey DP: TRP channels in mechanosensation: direct or indirect activation? Nat Rev Neurosci 2007;8:510-521.

148 Patel A, Sharif-Naeini R, Folgering JR, Bichet D, Duprat F, Honore E: Canonical TRP channels and mechanotransduction: from physiology to disease states. Pflugers Arch 2010;460:571-581.

149 Pedersen SF, Owsianik G, Nilius B: TRP channels: an overview. Cell Calcium 2005;38:233-252.

150 Minke B, Cook B: TRP channel proteins and signal transduction. Physiol Rev 2002;82:429-472.

151 Allen DG, Whitehead NP, Yeung EW: Mechanisms of stretch-induced muscle damage in normal and dystrophic muscle: role of ionic changes. J Physiol 2005;567:723-735.

152 Lammerding J, Kamm RD, Lee RT: Mechanotransduction in cardiac myocytes. Ann N Y Acad Sci 2004;1015:53-70.

153 Ervasti JM, Campbell KP: A role for the dystrophin-glycoprotein complex as a transmembrane linker between laminin and actin. J Cell Biol 1993;122:809-823.

154 Bertorini TE, Bhattacharya SK, Palmieri GM, Chesney CM, Pifer D, Baker B: Muscle calcium and magnesium content in Duchenne muscular dystrophy. Neurology 1982;32:1088-1092.

155 Franco-Obregon A Jr, Lansman JB: Mechanosensitive ion channels in skeletal muscle from normal and dystrophic mice. J Physiol 1994;481:299-309.

156 Turner PR, Fong PY, Denetclaw WF, Steinhardt RA: Increased calcium influx in dystrophic muscle. J Cell Biol 1991;115:1701-1712.

157 Lansman JB, Franco-Obregon A: Stretch-inactivated Channels in Skeletal Muscle; in (Kamkin A, and Kiseleva I, eds) Mechanosensitivity in Cells and Tissues. Moscow, 2005.

158 Claflin DR, Brooks SV: Direct observation of failing fibers in muscles of dystrophic mice provides mechanistic insight into muscular dystrophy. Am J Physiol Cell Physiol 2008;294:C651-658.

159 Morabito C, Rovetta F, Bizzarri M, Mazzoleni G, Fano G, Mariggio MA: Modulation of redox status and calcium handling by extremely low frequency electromagnetic fields in C2C12 muscle cells: A real-time, single-cell approach. Free Radic Biol Med 2010;48:579-589.

160 Saimi Y, Kung C: Calmodulin as an ion channel subunit. Annu Rev Physiol 2002;64:289-311.

161 Rychkov G, Barritt GJ: TRPC1 $\mathrm{Ca}^{2+}$-permeable channels in animal cells. Handb Exp Pharmacol 2007;179:23-52.

162 Formigli L, Sassoli C, Squecco R, Bini F, Martinesi M, Chellini F, Luciani G, Sbrana F, Zecchi-Orlandini S, Francini F, Meacci E: Regulation of transient receptor potential canonical channel 1 (TRPC1) by sphingosine 1-phosphate in $\mathrm{C} 2 \mathrm{C} 12$ myoblasts and its relevance for a role of mechanotransduction in skeletal muscle differentiation. J Cell Sci 2009;122:1322-1333.

163 Takamori M: Autoantibodies against TRPC3 and ryanodine receptor in myasthenia gravis. J Neuroimmunol 2008;200:142-144. 
164 Yu Y, Fantozzi I, Remillard CV, Landsberg JW, Kunichika N, Platoshyn O, Tigno DD, Thistlethwaite PA, Rubin LJ, Yuan JX: Enhanced expression of transient receptor potential channels in idiopathic pulmonary arterial hypertension. Proc Natl Acad Sci USA 2004;101:13861-13866.

165 Beech DJ: TRPC1: store-operated channel and more. Pflugers Arch 2005;451:53-60.

166 Dietrich A, Gudermann T: Trpc6. Handb Exp Pharmacol 2007;179:125-141.

167 Ge R, Tai Y, Sun Y, Zhou K, Yang S, Cheng T, Zou Q, Shen F, Wang Y: Critical role of TRPC6 channels in VEGFmediated angiogenesis. Cancer Lett 2009;283:43-51.

168 Kumar B, Dreja K, Shah SS, Cheong A, Xu SZ, Sukumar P, Naylor J, Forte A, Cipollaro M, McHugh D, Kingston PA, Heagerty AM, Munsch CM, Bergdahl A, Hultgardh-Nilsson A, Gomez MF, Porter KE, Hellstrand P, Beech DJ: Upregulated TRPC1 channel in vascular injury in vivo and its role in human neointimal hyperplasia. Circ Res 2006;98:557-563.

169 Bush EW, Hood DB, Papst PJ, Chapo JA, Minobe W, Bristow MR, Olson EN, McKinsey TA: Canonical transient receptor potential channels promote cardiomyocyte hypertrophy through activation of calcineurin signaling. J Biol Chem 2006;281:33487-33496.

170 Spassova MA, Hewavitharana T, Xu W, Soboloff J, Gill DL: A common mechanism underlies stretch activation and receptor activation of TRPC6 channels. Proc Natl Acad Sci USA 2006;103:16586-16591.

171 Arniges M, Vazquez E, Fernandez-Fernandez JM, Valverde MA: Swelling-activated Ca2+ entry via TRPV4 channel is defective in cystic fibrosis airway epithelia. J Biol Chem 2004;279:54062-54068.

172 Numata T, Shimizu T, Okada Y: TRPM7 is a stretch- and swelling-activated cation channel involved in volume regulation in human epithelial cells. Am J Physiol Cell Physiol 2007;292:C460-467.

173 Nauli SM, Zhou J: Polycystins and mechanosensation in renal and nodal cilia. Bioessays 2004;26:844-856.

174 Hogan PG, Chen L, Nardone J, Rao A: Transcriptional regulation by calcium, calcineurin, and NFAT. Genes Dev 2003;17:2205-2232.

175 Beals CR, Clipstone NA, Ho SN, Crabtree GR: Nuclear localization of NF-ATc by a calcineurin-dependent, cyclosporin-sensitive intramolecular interaction. Genes Dev 1997;11:824-834.

176 Dolmetsch RE, Lewis RS, Goodnow CC, Healy JI: Differential activation of transcription factors induced by Ca2+ response amplitude and duration. Nature 1997;386:855-858.

177 Horsley V, Pavlath GK: NFAT: ubiquitous regulator of cell differentiation and adaptation. J Cell Biol 2002;156:771-774.

178 Musaro A, McCullagh KJ, Naya FJ, Olson EN, Rosenthal N: IGF-1 induces skeletal myocyte hypertrophy through calcineurin in association with GATA-2 and NF-ATc1. Nature 1999;400:581-585.

179 Semsarian C, Wu MJ, Ju YK, Marciniec T, Yeoh T, Allen DG, Harvey RP, Graham RM: Skeletal muscle hypertrophy is mediated by a Ca2+-dependent calcineurin signalling pathway. Nature 1999;400:576-581.

180 Chin ER, Olson EN, Richardson JA, Yang Q, Humphries C, Shelton JM, Wu H, Zhu W, Bassel-Duby R, Williams RS: A calcineurin-dependent transcriptional pathway controls skeletal muscle fiber type. Genes Dev 1998;12:2499-2509.

-181 Kubis HP, Hanke N, Scheibe RJ, Meissner JD, Gros G: $\mathrm{Ca}^{2+}$ transients activate calcineurin/NFATc1 and initiate fast-to-slow transformation in a primary skeletal muscle culture. Am J Physiol Cell Physiol 2003;285:C5663.

182 Olson EN, Williams RS: Remodeling muscles with calcineurin. Bioessays 2000;22:510-519.

183 McCullagh KJ, Calabria E, Pallafacchina G, Ciciliot S, Serrano AL, Argentini C, Kalhovde JM, Lomo T, Schiaffino S: NFAT is a nerve activity sensor in skeletal muscle and controls activity-dependent myosin switching. Proc Natl Acad Sci USA 2004;101:10590-10595.

184 Valdes JA, Gaggero E, Hidalgo J, Leal N, Jaimovich E, Carrasco MA: NFAT activation by membrane potential follows a calcium pathway distinct from other activity-related transcription factors in skeletal muscle cells. Am J Physiol Cell Physiol 2008;294:C715-725.

185 Pigozzi D, Ducret T, Tajeddine N, Gala JL, Tombal B, Gailly P: Calcium store contents control the expression of TRPC1, TRPC3 and TRPV6 proteins in LNCaP prostate cancer cell line. Cell Calcium 2006;39:401-415.

186 Wu H, Rothermel B, Kanatous S, Rosenberg P, Naya FJ, Shelton JM, Hutcheson KA, DiMaio JM, Olson EN, Bassel-Duby R, Williams RS: Activation of MEF2 by muscle activity is mediated through a calcineurindependent pathway. EMBO J 2001;20:6414-6423.

187 Wu H, Naya FJ, McKinsey TA, Mercer B, Shelton JM, Chin ER, Simard AR, Michel RN, Bassel-Duby R, Olson EN, Williams RS: MEF2 responds to multiple calcium-regulated signals in the control of skeletal muscle fiber type. ЕMBO J 2000;19:1963-1973. 
188 Bigard X, Sanchez H, Zoll J, Mateo P, Rousseau V, Veksler V, Ventura-Clapier R: Calcineurin Co-regulates contractile and metabolic components of slow muscle phenotype. J Biol Chem 2000;275:19653-19660.

189 Liu Y, Cseresnyes Z, Randall WR, Schneider MF: Activity-dependent nuclear translocation and intranuclear distribution of NFATc in adult skeletal muscle fibers. J Cell Biol 2001;155:27-39.

190 Calabria E, Ciciliot S, Moretti I, Garcia M, Picard A, Dyar KA, Pallafacchina G, Tothova J, Schiaffino S, Murgia M: NFAT isoforms control activity-dependent muscle fiber type specification. Proc Natl Acad Sci U S A 2009;106:13335-13340.

191 Abbott KL, Friday BB, Thaloor D, Murphy TJ, Pavlath GK: Activation and cellular localization of the cyclosporine A-sensitive transcription factor NF-AT in skeletal muscle cells. Mol Biol Cell 1998;9:29052916.

192 Horsley V, Pavlath GK: Forming a multinucleated cell: molecules that regulate myoblast fusion. Cells Tissues Organs 2004;176:67-78.

193 Rauch C, Loughna PT: Cyclosporin-A inhibits stretch-induced changes in myosin heavy chain expression in C2C12 skeletal muscle cells. Cell Biochem Funct 2006;24:55-61.

194 Yang H, Alnaqeeb M, Simpson H, Goldspink G: Changes in muscle fibre type, muscle mass and IGF-I gene expression in rabbit skeletal muscle subjected to stretch. J Anat 1997;190:613-622.

195 Robinson MJ, Cobb MH: Mitogen-activated protein kinase pathways. Curr Opin Cell Biol 1997;9:180-186.

196 Roux PP, Blenis J: ERK and p38 MAPK-activated protein kinases: a family of protein kinases with diverse biological functions. Microbiol Mol Biol Rev 2004;68:320-344.

197 Seger R, Krebs EG: The MAPK signaling cascade. FASEB J 1995;9:726-735.

198 Kumar A, Khandelwal N, Malya R, Reid MB, Boriek AM: Loss of dystrophin causes aberrant mechanotransduction in skeletal muscle fibers. FASEB J 2004;18:102-113.

199 Kippenberger S, Bernd A, Loitsch S, Guschel M, Muller J, Bereiter-Hahn J, Kaufmann R: Signaling of mechanical stretch in human keratinocytes via MAP kinases. J Invest Dermatol 2000;114:408-412.

200 Yamazaki T, Komuro I, Shiojima I, Yazaki Y: The molecular mechanism of cardiac hypertrophy and failure. Ann N Y Acad Sci 1999;874:38-48.

201 Ishida T, Peterson TE, Kovach NL, Berk BC: MAP kinase activation by flow in endothelial cells. Role of beta 1 integrins and tyrosine kinases. Circ Res 1996;79:310-316.

202 Keren A, Tamir Y, Bengal E: The p38 MAPK signaling pathway: a major regulator of skeletal muscle development. Mol Cell Endocrinol 2006;252:224-230.

203 Lluis F, Perdiguero E, Nebreda AR, Munoz-Canoves P: Regulation of skeletal muscle gene expression by p38 MAP kinases. Trends Cell Biol 2006;16:36-44.

204 Goodyear LJ, Chang PY, Sherwood DJ, Dufresne SD, Moller DE: Effects of exercise and insulin on mitogenactivated protein kinase signaling pathways in rat skeletal muscle. Am J Physiol 1996;271:E403-408.

205 Aronson D, Dufresne SD, Goodyear LJ: Contractile activity stimulates the c-Jun NH2-terminal kinase pathway in rat skeletal muscle. J Biol Chem 1997;272:25636-25640.

206 Kook SH, Lee HJ, Chung WT, Hwang IH, Lee SA, Kim BS, Lee JC: Cyclic mechanical stretch stimulates the proliferation of C2C12 myoblasts and inhibits their differentiation via prolonged activation of p38 MAPK. Mol Cells 2008;25:479-486.

207 Nakai N, Kawano F, Oke Y, Nomura S, Ohira T, Fujita R, Ohira Y: Mechanical stretch activates signaling events for protein translation initiation and elongation in C2C12 myoblasts. Mol Cells 2010;30:513-518.

208 Zhu X, Assoian RK: Integrin-dependent activation of MAP kinase: a link to shape-dependent cell proliferation. Mol Biol Cell 1995;6:273-282.

209 Gebken J, Luders B, Notbohm H, Klein HH, Brinckmann J, Muller PK, Batge B: Hypergravity stimulates collagen synthesis in human osteoblast-like cells: evidence for the involvement of p44/42 MAP-kinases (ERK 1/2). J Biochem 1999;126:676-682.

210 Schnoke M, Midura RJ: Pulsed electromagnetic fields rapidly modulate intracellular signaling events in osteoblastic cells: comparison to parathyroid hormone and insulin. J Orthop Res 2007;25:933-940.

-211 Wang E, Zhao M, Forrester JV, McCaig CD: Bi-directional migration of lens epithelial cells in a physiological electrical field. Exp Eye Res 2003;76:29-37. 